\title{
Tidal Modulation of Surface Gravity Waves in the Gulf of Maine
}

\author{
PENGCHENG WANG AND JiNYU SHENG \\ Department of Oceanography, Dalhousie University, Halifax, Nova Scotia, Canada
}

(Manuscript received 28 November 2017, in final form 15 August 2018)

\begin{abstract}
This study examines the tidal modulation of surface gravity waves in the Gulf of Maine (GoM) by using in situ observations and numerical model results. Analysis of observational data demonstrates significant semidiurnal tidal modulations in the mean wave variables for swell-dominated waves in the region. The observed tidal modulation features significant spatial-temporal variabilities, with large magnitudes near the mouth of the GoM. Observations also demonstrate unusual timing of the maximum modulation of significant wave height $H_{s}$ in the following tidal currents. The coupled wave-circulation model successfully reproduces the observed tidal modulation and the associated spatial-temporal variabilities. Model results demonstrate that the maximum $H_{s}$ modulations are first generated during the maximum flood tide or ebb tide near the mouth of the GoM and then propagate onto the inner gulf. Around the mouth of the GoM, tidal currents have strong spatial gradients, resulting in great effects of current-induced convergence, refraction, and wavenumber shift. The tidal modulation in $H_{s}$ generated by convergence $(10 \%-14 \%)$ is less affected by the wave propagation direction than the modulation generated by the wavenumber shift $(6 \%-10 \%)$ and refraction $(4 \%-20 \%)$. The latter modulation varies significantly with changes in the wave propagation direction. In addition, current-enhanced dissipation becomes important during high winds, which reduces at least one-half of the $H_{s}$ modulation during the study period. The observed unusual timing of the maximum $H_{s}$ modulation in the following tidal currents can be mostly explained by the convergence and wavenumber shift associated with wave-energy convergence and energy transfer from currents to waves in spatially decelerating currents.
\end{abstract}

\section{Introduction}

Large tidal currents are known to modulate the behavior of wind-generated surface gravity waves at tidal frequencies (Vincent 1979). With the conventional theory of wave-current interaction (WCI), one would expect that the tidal modulation in the wave height should reach its maximum in the "contra" (opposing) tidal currents. By contrast, however, higher waves were frequently observed in the following tidal currents than those in the contra tidal currents (e.g., Gemmrich and Garrett 2012; Guillou and Chapalain 2012; Vincent 1979). Using a simple analytical model, Davidson et al. (2008) demonstrated that wave dissipation resulting from the opposing tidal currents could be responsible for the unusual timing of the maximum wave height (about 50-60 min, just after the maximum flooding tidal currents) in the macrotidal areas. Nonetheless, the important physical processes affecting the unusual timing of the maximum wave height are complex and differ over different areas.

Corresponding authors: Pengcheng Wang, pengcheng.wang@ dal.ca; Jinyu Sheng, jinyu.sheng@dal.ca
Previous studies suggested that ocean surface currents can modify the relative wind speeds above the sea surface (the relative wind effect) and change the absolute frequency of surface waves, known as the Doppler shift. Spatial variability of surface currents can modify the relative wave frequency and cause wave refraction, shoaling, and breaking that mimic bathymetric effects. Furthermore, the variation of sea surface elevations can modify the local water depth and thus affect the wave propagation and dissipation. Previous studies also demonstrated some important effects of these WCI mechanisms on tidal modulations in ocean surface waves. For an example, Ardhuin et al. (2012) showed that for wind-generated surface waves the relative wind effect explained about $20 \%-40 \%$ of the modulation in wave heights by periodic changes in the effective wind speeds induced by tidal currents. Bolaños et al. (2014) demonstrated that in shallow waters of a tidally dominated estuary the tidal modulation in the wave height was mainly controlled by the time-varying water depth. Masson (1996) showed that the current-induced refraction affected the phase of the tidal modulation in the wave height off the British Columbia coast. Tolman (1990) 
found that effects of current-induced refraction were negligible in the North Sea. Tolman (1990) also found that during strong storm events the effects of surface currents and water level variations approximately balanced each other out, resulting in much smaller tidal modulations of surface waves than in moderate wind cases. Moon (2005) demonstrated that tidal modulations in the mean wave variables decreased with increasing severity of winds. Thus, contributions of different WCI mechanisms to tidal modulations in surface waves depend largely on the local bathymetry, winds, waves, and tidal conditions.

The study region of this paper is the Gulf of Maine (GoM), which is a large semienclosed coastal basin bordered by the northeastern United States and the Canadian Maritime Provinces. The GoM is recognized as one of the world's richest marine ecosystems, with various marine and estuarine habitats (Johnson et al. 2011). Reliable modeling and predictions of marine environmental conditions are needed for effective ecosystem management of natural resources in the region.

The GoM is characterized by large semidiurnal $\mathrm{M}_{2}$ tidal currents, with the world's largest tidal range of $\sim 16 \mathrm{~m}$ in the upper reaches of the Bay of Fundy (Greenberg 1983; Hasegawa et al. 2011). The semidiurnal tidal currents are also strong and can be up to $1.0 \mathrm{~m} \mathrm{~s}^{-1}$ over the mouth of the GoM. The general physical oceanography of the GoM can be found elsewhere (Bigelow et al. 1927; Xue et al. 2000; He et al. 2008; Smith et al. 2012; Li et al. 2014).

The main topographic feature over the mouth of the GoM includes the Georges Bank (GB), Northeast Channel, and Great South Channel. The GB is a large shallow submarine bank, and the Northeast and Great South Channels are two deep channels in the region (Fig. 1). Since the mouth of the GoM is exposed to large swells coming from the North Atlantic Ocean, strong tidal modulations in ocean surface waves are expected to occur. In-depth knowledge on tidal modulations of surface waves is important for accurate and reliable surface wave modeling and predictions in the GoM. The scientific issues on tidal modulations of surface waves in the study region, however, were not addressed until recently. Sun et al. (2013) showed that effects of ocean currents on waves were insignificant at buoys located in the inner GoM during a hurricane event. On the contrary, Xie and Zou (2016) demonstrated large impacts of ocean currents on wave heights on GB during a storm event based on numerical results. It is noted that these two studies focused mainly on short time scales associated with a single storm event. The relevant mechanisms controlling the wave modulation by tidal currents in the study region have not been fully addressed.

The long-term wave buoy measurements and newly developed coupled wave-circulation model in the GoM provide us with a unique opportunity to examine tidal modulations of surface waves as well as the relevant physical processes controlling them in the region. The analysis of observational data is presented in the following section. The coupled wave-circulation model is described in section 3. The comparison of model results with observations is presented in section 4 . The examination of relevant physical processes controlling the tidal modulation in the region is provided in section 5 . The conclusions and summary are given in section 6 .

\section{Analysis of observational data}

In situ surface wave observations at four operational wave buoys $(44027,44005,44018$, and 44008) in the GoM (Fig. 1) are used in this study. The data were observed by $3-\mathrm{m}$ discus buoys operated by the National Data Buoy Center (NDBC). These buoys were equipped with the AMPS (Advance Modular Payload System; i.e., onboard processor) to acquire and transmit NDBC measurements. (See http://www.ndbc.noaa.gov/rsa.shtml for the system accuracy of AMPS.) The buoy sensors were calibrated by the NDBC prior to deployment and replaced with calibrated instruments every two years. These buoys reported hourly measurements of nondirectional wave variables, that is, the significant wave height $H_{s}$, the peak wave period $T_{p}$, and the average wave period, derived from the measured spectral wave density over a 20-min acquisition period. Starting from 2007, buoys 44008 and 44018 have also reported directional wave data from which the mean wave directions $\theta_{m}$ were derived. Automated quality control procedures were used to ensure the accuracy of the NDBC measurements. Transmission parity error, range limit, time continuity, and internal consistency checks were performed. See NDBC (2009) for more detailed information on the NDBC's quality control technique.

In situ wind measurements were made at these operational buoys using four-blade, impeller-driven, wind-vane sensors (NDBC 2009). Hourly wind vector data were reported based on time series of instantaneous wind samples taken at a minimum rate of $1-\mathrm{Hz}$ measurements over an 8-min acquisition period. Wind measurements underwent range, consistency, standard deviation, and gust-tospeed-ratio checks. In situ ocean current measurements were also made at buoys 44027 and 44008 . However, these current measurements were sparse and were only available for a few months, which limits their applicability in our study.

Direct water level measurements at these four buoys are not available during the study period. Instead, the tidal elevations predicted by the Oregon State University Tidal Inversion Software (OTIS) at these buoy 


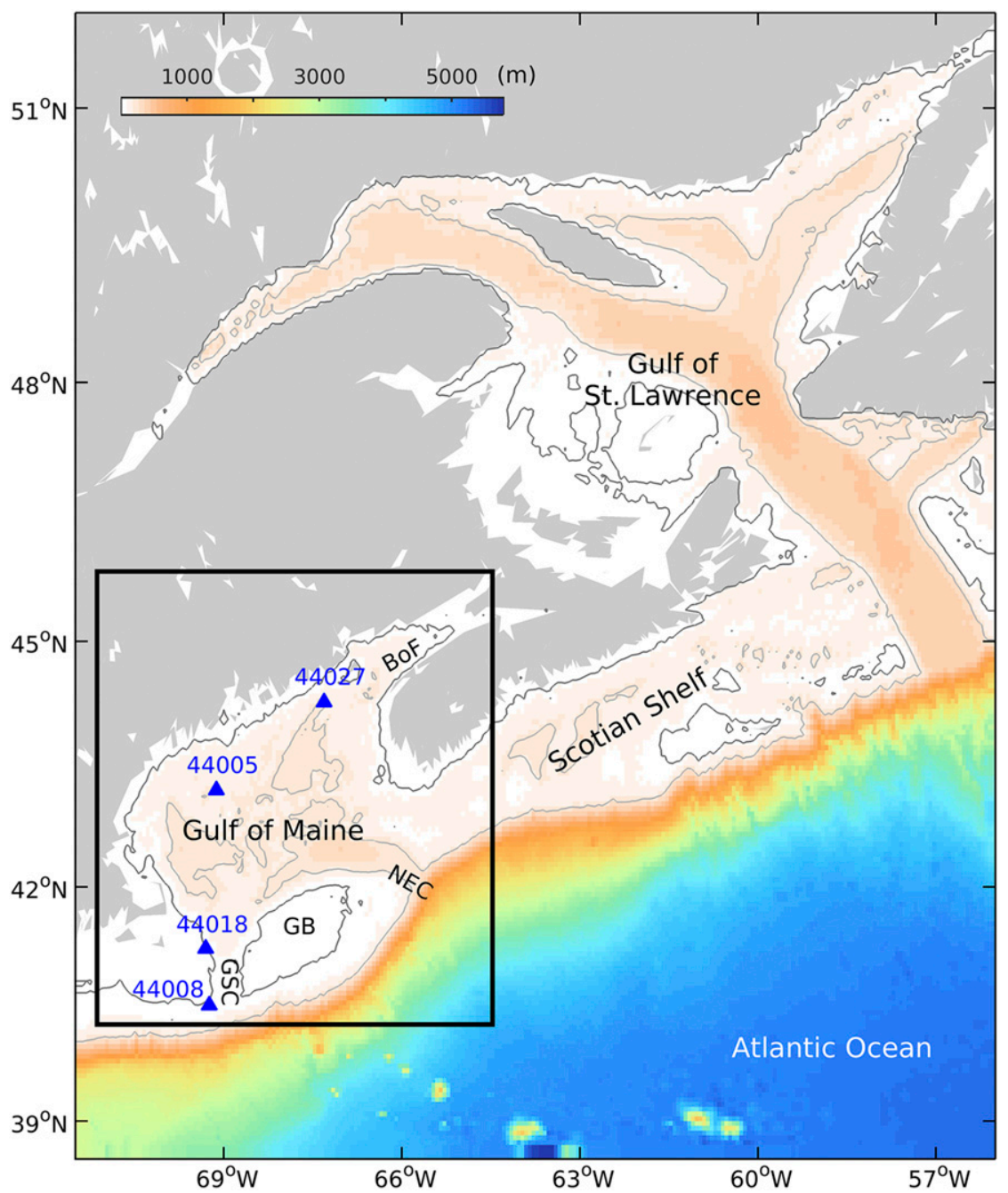

FIG. 1. Map showing the model domain. The black box denotes the study area of the Gulf of Maine. The blue triangles denote wave buoy locations, and the black and gray contour lines respectively represent the 60- and 200-m isobaths. Abbreviations are used for the Bay of Fundy (BoF), Northeast Channel (NEC), Georges Bank (GB), and Great South Channel (GSC).

locations are used in this study. The OTIS solutions used an inverse data assimilation approach to incorporate all different types of observed tidal data into a regional finitedifference tidal model (Egbert and Erofeeva 2002). Therefore, the OTIS solutions can be considered as a reanalysis of the two-dimensional tidal circulation, which is capable of providing reliable predictions of tidal surface elevations and depth-mean tidal currents in the study region.

Last, note that two buoys (44018 and 44005) underwent several considerable location changes since initial deployments (Table 1). In particular, since 2011, buoy 44018 has been relocated from $41.3^{\circ} \mathrm{N}, 69.3^{\circ} \mathrm{W}$ to be farther to the northwest $\left(42.2^{\circ} \mathrm{N}, 69.8^{\circ} \mathrm{W}\right)$. At this latter location, the observed tidal modulations of mean wave variables were found to be weaker than they were before.
Considering the location changes of these buoys, the study period in this section is chosen to be the duration between January 2008 and December 2010.

\section{a. Spectral content}

Spectral analysis was performed by taking the fast Fourier transform of the demeaned and detrended 3-yr $H_{s}$ and wind speed time series at four buoys (Figs. 2a,b). The spectral estimates were smoothed using a Parzen window with a bandwidth of 0.104 cycles per day (cpd). Both the $H_{s}$ and wind speed spectra at four buoys have large power at low frequencies corresponding to a period of 5-10 days, which is mainly associated with typical time scales of winter storms passing over the GoM. In addition, all of the spectra of $H_{s}$ feature sharp peaks at 
TABLE 1. Location changes of four NDBC buoys.

\begin{tabular}{|c|c|c|c|c|c|c|c|}
\hline \multicolumn{2}{|l|}{44018} & \multicolumn{2}{|l|}{44008} & \multicolumn{2}{|l|}{44005} & \multicolumn{2}{|c|}{44027} \\
\hline Date & Lat/lon & Date & Lat/lon & Date & Lat/lon & Date & Lat/lon \\
\hline Jul 2002-Aug 2011 & $41.3^{\circ}-69.3^{\circ}$ & Aug 1982-Oct 2008 & $40.5^{\circ}-69.4^{\circ}$ & Dec 1978-Mar 1988 & $42.7^{\circ}-68.3^{\circ}$ & May 2003-now & $44.3^{\circ} /-67.3^{\circ}$ \\
\hline Oct 2011-Dec 2011 & $42.2^{\circ}-69.8^{\circ}$ & Nov 2008-now & $40.5^{\circ} /-69.2^{\circ}$ & Jun 1988-Aug 1991 & $42.7^{\circ}-68.6^{\circ}$ & & \\
\hline Feb 2012-Mar 2012 & $42.1^{\circ}-69.6^{\circ}$ & & & Jan 1992-Jan 1994 & $42.6^{\circ}-68.6^{\circ}$ & & \\
\hline \multirow[t]{3}{*}{ Apr 2015-now } & $42.1^{\circ} /-69.7^{\circ}$ & & & Apr 1994-Mar 2001 & $42.9^{\circ} /-68.9^{\circ}$ & & \\
\hline & & & & Mar 2001-Dec 2010 & $43.2^{\circ}-69.2^{\circ}$ & & \\
\hline & & & & Jan 2011-now & $43.2^{\circ}-69.1^{\circ}$ & & \\
\hline
\end{tabular}

the semidiurnal tidal frequency $\mathrm{M}_{2}$ of $1.93 \mathrm{cpd}$. Because there are no corresponding peaks in the wind speed spectra, the results in Fig. 2a suggest the influence of tidal currents. The extra semidiurnal variance in the $H_{s}$ spectrum is about $0.05 \mathrm{~m}^{2}$ (corresponding to an average $H_{s}$ modulation of $0.22 \mathrm{~m}$ ) at buoy 44018 , which is much larger than the $0.003 \mathrm{~m}^{2}$ reported in a tidal channel of western Canada by Gemmrich and Garrett (2012). It is also much larger than the extra semidiurnal variances (less than $0.006 \mathrm{~m}^{2}$ ) calculated at the other three buoys in this study. In addition, different from Gemmrich and Garrett (2012) who found the signature of inertial currents in offshore wave records, there are no evident inertial peaks in all the spectra of $H_{s}$, indicating that inertial motions were not significant at these buoy locations.

Figures $2 \mathrm{c}$ and $2 \mathrm{~d}$ present the cross-spectra analysis of the $H_{s}$ and time series of tidal elevation. At these four buoys the coherences between these two time series at the semidiurnal frequency exceed 0.4 , which are significantly different from zero at the $1 \%$ significance level (Fig. 2c). This confirms that the semidiurnal $H_{s}$ peaks are mainly induced by the $\mathrm{M}_{2}$ tide. The phase relationships between two signals (Fig. 2d) show different phase lags at the semidiurnal frequency at four buoys, indicating that the semidiurnal $H_{s}$ peak could occur at different times (or phases) relative to the local tide. A phase lag of about $-50^{\circ}$ at buoy 44018 , for example, indicates that the maximum $H_{s}$ occurred about $1.4 \mathrm{~h}$ after the maximum flood or about $1.7 \mathrm{~h}$ before the slack tide. Thus, higher waves occur in the following tidal currents at this particular location, similar to those reported in previous studies (e.g., Davidson et al. 2008; Gemmrich and Garrett 2012). In a later part of the paper, a coupled wave-circulation model is used to further examine this issue.

\section{b. Temporal variability}

We next examine the observational data at buoy 44018 where the observed semidiurnal tidal modulations were the most significant among the four buoys. Figures $3 \mathrm{a}, 3 \mathrm{c}$, and $3 \mathrm{e}$ present the 3 -yr $H_{s}$ time series at this buoy. These figures demonstrate large seasonal variations of $H_{s}$ associated with high sea states from October to April and low sea states from May to September. To examine the temporal variability of tidal modulation in $H_{s}$, we present in Figs. 3b, 3d, and $3 \mathrm{f}$ the time-evolving spectrum of $H_{S}$ in the semidiurnal band calculated using MATLAB's spectrogram function. Individual spectra were calculated from the $H_{s}$ time series within a 10-day time window with a 2.5 -day increment. The semidiurnal power in the time-evolving spectrum changed with time, and strong tidal modulations occurred during high sea states (e.g., March, April, and November 2010). However, the magnitude of tidal modulation was not simply correlated with the $H_{s}$ magnitude. In many cases, the magnitudes of tidal modulation during high sea states were similar to those during low sea states. This suggests that different wave types (i.e., wind sea and swell) might play an important role in the tidal modulation.

We next examine the individual $H_{s}$ oscillations during a selected low-sea-state period (August 2010) and a highsea-state period (November 2010). To quantitatively distinguish the wind seas and swells, we follow Hanley et al. (2010) and use criteria that are based on the inverse wave age defined as

$$
A^{-1}=\left(\mathbf{U}_{10} \cos \theta_{r}\right) / C_{p},
$$

where $\mathbf{U}_{10} \cos \theta_{r}$ is the projection of the $10-\mathrm{m}$ wind velocity in the direction of wave propagation, $\theta_{r}$ is the relative angle between the winds and the waves, and $C_{p}$ is the phase speed at the spectral peak defined as $C_{p}=$ $g T_{p} /(2 \pi)$. According to Hanley et al. (2010), surface waves start to grow by absorbing momentum from the wind when $A^{-1}>0.83$, and fast-moving waves start to impart momentum to the wind when $A^{-1}<0.15$. Therefore, three wave types can be identified from

$$
\left\{\begin{array}{cl}
\text { Swell: } & A^{-1}<0.15 \\
\text { Intermediate waves: } & 0.15<A^{-1}<0.83 . \\
\text { Wind sea: } & A^{-1}>0.83
\end{array}\right.
$$

Figure 4 presents time series of observed wind stress, $H_{s}, T_{p}, \theta_{m}$, and values of $A^{-1}$ calculated from the wave data at buoy 44018 in August and November of 2010. 

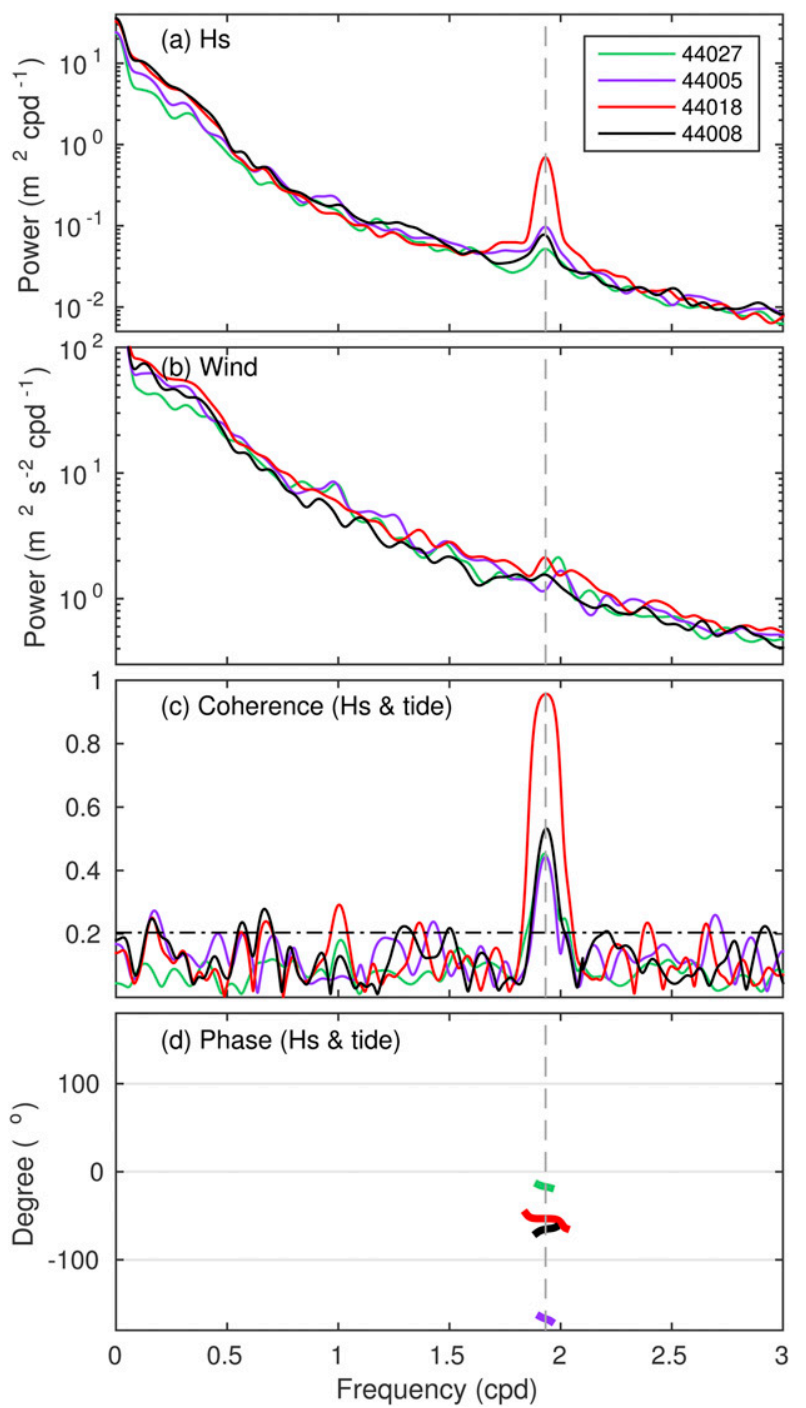

FIG. 2. Power spectra of observed time series of (a) significant wave heights and (b) wind speeds at four buoys in years 2008-10. Also shown is a cross-spectra analysis between time series of significant wave heights and tidal levels with (c) coherence (the dashdotted line is the $1 \%$ significant level for zero coherence) and (d) phase (plotted for coherent points only). The vertical dashed lines represent the semidiurnal tidal frequency.

The wind stress was converted from the observed wind speed using the bulk formula of Large and Pond (1981). From the values of $A^{-1}$ shown in Figs. $4 \mathrm{i}$ and $4 \mathrm{j}$, the surface waves were dominated by swells when the local wind was weak and by wind seas when the local wind was strong. In August of 2010 (except for times around 23 August), the local winds were relatively weak at buoy 44018 , and the low-frequency (subtidal) variabilities at this buoy were characterized by relatively low values of $H_{s}$ (less than $2.5 \mathrm{~m}$ ), long wave periods $T_{p}$ (larger than $\sim 7 \mathrm{~s}$ ), and stable wave propagation directions $\left(70^{\circ}-190^{\circ}\right)$. These low-frequency variabilities in the surface waves during this period were associated mostly with swells forced by remote wind forcing. Around 23 August, a strong local wind event occurred and wind sea was dominant with $H_{s}$ up to $4.0 \mathrm{~m}$ and relatively short $T_{p}$ of $\sim 5.0 \mathrm{~s}$. In November of 2010, the low-frequency variabilities of surface wave variables were highly correlated with the local wind. The wave field was generally swell-dominated in the first half of the month (before 18 November), with relatively longer $T_{p}$ (larger than $\sim 7 \mathrm{~s}$ ) and stable wave directions. The wind sea dominated in the last half of November of 2010 with shorter $T_{p}$ (less than $\sim 7 \mathrm{~s}$ ) and dramatically changed wave directions.

In addition to the low-frequency variabilities discussed above, the observed surface wave variables shown in Figs. 4c-4h also feature high-frequency oscillations (or modulations) at periods of nearly 0.5 days during these two months. The amplitudes of the highfrequency (semidiurnal) oscillations in $H_{s}$ can reach $\sim 0.5 \mathrm{~m}$, which is more than 2 times the average value $(0.22 \mathrm{~m})$ obtained from the spectral estimates of the 3-yr $H_{s}$ record. The amplitudes of the semidiurnal oscillations in $T_{p}$ and $\theta_{m}$ can reach $3.0 \mathrm{~s}$ and $25^{\circ}$, respectively. One interesting feature in November 2010 is that the semidiurnal oscillations in the observed surface waves were much stronger with swell-dominated surface waves in the first half of the month than those with wind-sea-dominated waves in the last half of the month. It is noted that the semidiurnal oscillations were also weak during the relatively strong wind event around 23 August when the wave field was dominated by wind seas. This indicates that the semidiurnal oscillations of surface waves depend strongly on the wave type. The swell-dominated surface waves associated with relatively stable wave-propagation directions are favorable for the generation of these semidiurnal oscillations induced by tidal currents. This conclusion is also found to be valid for other periods of the 3-yr record.

To examine the relationship between $H_{s}$ and tides in the time domain further, we consider time series of tidal elevation and $H_{s}$ at buoy 44018 on 3-19 August 2010, shown in Fig. 5. During this period with swelldominated waves, almost every tidal cycle was associated with a modulation of $H_{s}$. Moreover, a consistent phase relationship occurs between these two signals, with the maximum $H_{s}$ modulation occurring during the flood tide (i.e., in the following tidal currents). These results are consistent with the spectral analysis presented in Figs. $2 \mathrm{c}$ and $2 \mathrm{~d}$.

\section{A coupled wave-circulation model and model forcing}

The coupled wave-circulation model developed by Wang and Sheng (2016) was used in this study. The 

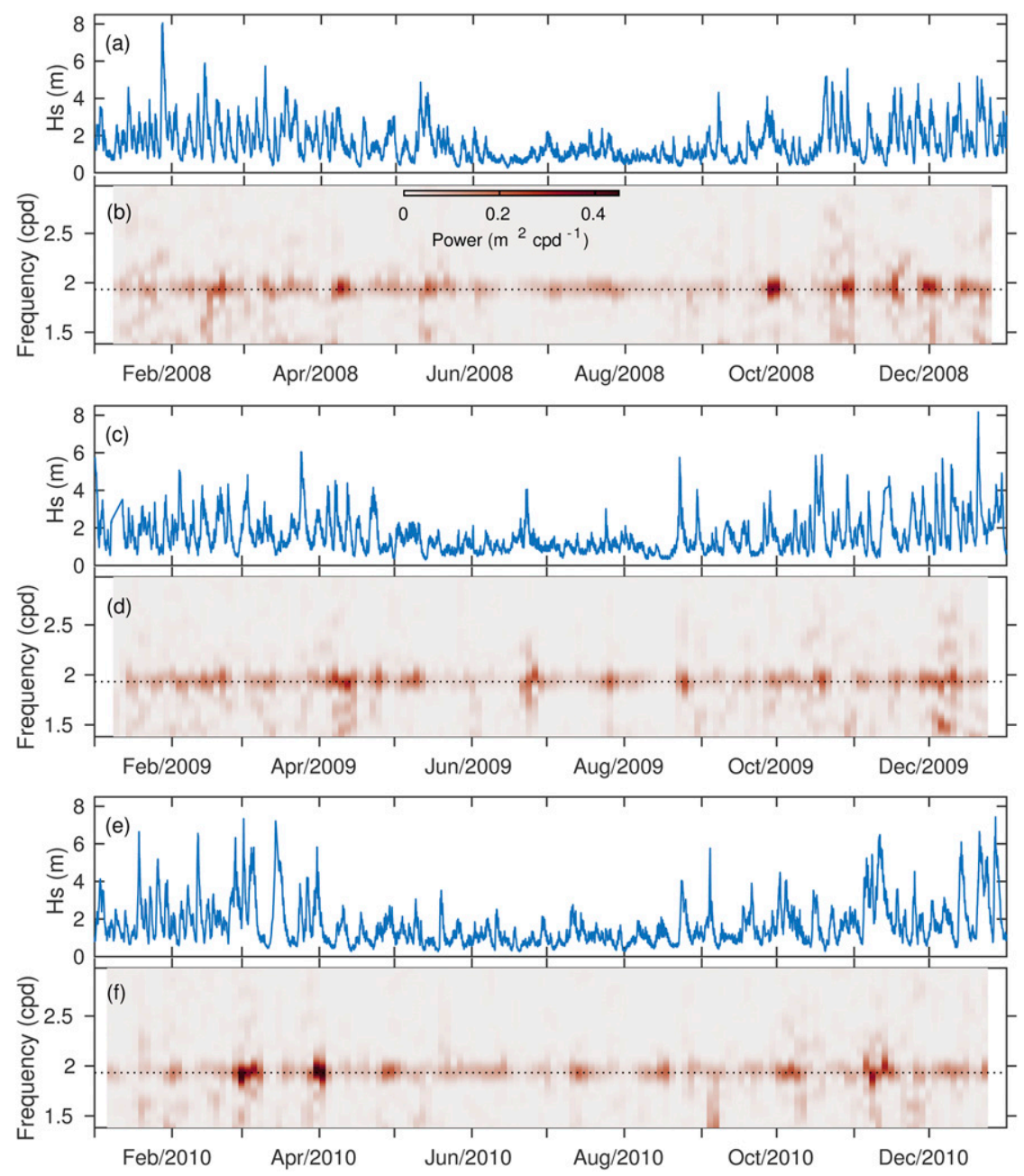

FIG. 3. (a),(c),(e) Time series of observed significant wave heights at buoy 44018 in years 2008-10 and (b),(d),(f) corresponding time-evolving spectra of observed significant wave heights in the semidiurnal band calculated using a 10-day sliding window with a 2.5 -day increment. The horizontal dashed lines in (b), (d), and (f) represent the semidiurnal tidal frequency.

coupled model consists of a 3D ocean circulation model known as the Dalhousie Coastal Ocean Prediction System (DalCoast) and a third-generation wave model known as WAVEWATCH III (WW3). The wave effects on the 3D circulation are specified in DalCoast using the vortex force formalism (Bennis et al. 2011) and the breaking-waveinduced mixing (Craig and Banner 1994). In WW3, the effects of ocean surface currents on surface waves include the relative wind effect, current-induced convergence, wavenumber shift, and refraction. The rest of the paper will focus on the selected low-sea-state period (August 2010) and high-sea-state period (November 2010).

\section{a. Circulation model}

As described in our previous paper (Wang and Sheng 2016), DalCoast is based on the Princeton Ocean Model
(POM; Mellor 2004). The latter is a 3D, sigma coordinate, primitive equation ocean circulation model. The model domain of DalCoast (Fig. 1) covers the Gulf of Saint Lawrence, the Scotian shelf, the GoM, and adjacent deep waters $\left(71.5^{\circ}-56^{\circ} \mathrm{W}, 38.5^{\circ}-52^{\circ} \mathrm{N}\right)$ with a horizontal resolution of $(1 / 16)^{\circ}(\sim 7 \mathrm{~km})$ in both the longitudinal and latitudinal directions. There are 40 sigma levels in the vertical direction; they are concentrated near the surface and bottom and are equally distributed in the interior. The model topography is based on the General Bathymetric Chart of the Oceans (GEBCO) bathymetry data (http://www.gebco.net).

The external forcing for DalCoast includes hourly surface winds and atmospheric pressures at sea level (SLP) extracted from the Climate Forecast System Reanalysis (Saha et al. 2010). Wind stress is calculated using a 


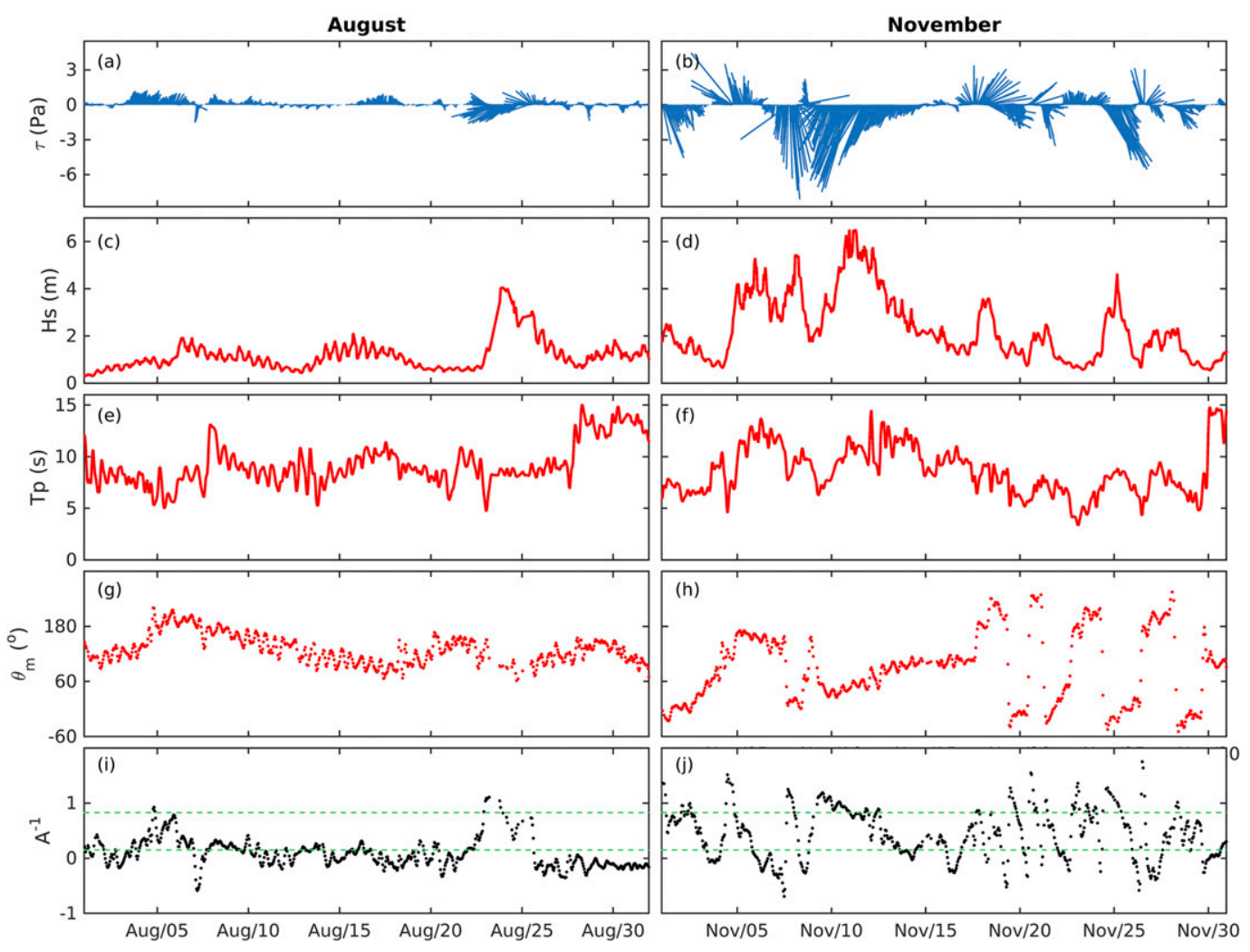

FIG. 4. Time series of observed (a),(b) wind stress; (c),(d) significant wave height; (e),(f) peak period; (g),(h) mean wave direction; and (i),(j) calculated inverse wave age at buoy 44018 in (left) August and (right) November 2010. The horizontal green dashed lines in (i) and (j) indicate two selected critical inverse wave age values for wind seas (0.83) and swells (0.15) (Hanley et al. 2010).

quadratic formula with drag coefficients given by the bulk formula of Large and Pond (1981). DalCoast is also driven by the net heat and freshwater fluxes at the sea surface and the freshwater runoff from major rivers in the region. At the model open boundaries, the model is driven by 1) storm-induced hourly sea level and depth-averaged currents simulated by a barotropic model covering the northwestern Atlantic Ocean $\left(72^{\circ}-42^{\circ} \mathrm{W}, 38^{\circ}-60^{\circ} \mathrm{N}\right)$ with a resolution of $\left.(1 / 12)^{\circ}, 2\right)$ tidal forcing specified in terms of hourly sea levels and depth-averaged currents predicted by OTIS, including eight tidal constituents $\left(\mathrm{M}_{2}, \mathrm{~S}_{2}, \mathrm{~N}_{2}\right.$, $\mathrm{K}_{2}, \mathrm{~K}_{1}, \mathrm{O}_{1}, \mathrm{P}_{1}$, and $\mathrm{Q}_{1}$ ), and 3) daily values of the $3 \mathrm{D}$ temperature, salinity, and large-scale density-driven currents provided by an ocean-ice numerical model of the northwestern Atlantic (Ohashi et al. 2009a,b; UrregoBlanco and Sheng 2012). Spectral nudging (Thompson et al. 2007) and the semiprognostic method (Sheng et al. 2001) are applied in DalCoast to reduce the seasonal bias in the model circulation and hydrography.

\section{b. Wave model}

WW3 is an operational wave model developed at the NOAA/National Centers for Environmental Prediction that solves the wave-action balance equation. In a Cartesian grid, the balance equation for the wave-action density spectrum $N(k, \theta)=F(k, \theta) / \sigma$ (where $F$ is the variance spectrum defined as a function of wavenumber $k$ and direction $\theta$ and $\sigma$ is the intrinsic frequency) in WW3 can be written (overdots indicate a derivative) as

$$
\begin{aligned}
\frac{\partial N}{\partial t}+\nabla & \cdot(\dot{\mathbf{x}} N)+\frac{\partial}{\partial k}(\dot{k} N)+\frac{\partial}{\partial \theta}(\dot{\theta} N)=\frac{S_{\text {tot }}}{\sigma}, \\
\dot{\mathbf{x}} & =\mathbf{c}_{g}+\mathbf{U}, \\
\dot{k} & =-\frac{\partial \sigma}{\partial D} \frac{\partial D}{\partial s}-\mathbf{k} \cdot \frac{\partial \mathbf{U}}{\partial s}, \quad \text { and } \\
\dot{\theta} & =-\frac{1}{k}\left(\frac{\partial \sigma}{\partial D} \frac{\partial D}{\partial m}+\mathbf{k} \cdot \frac{\partial \mathbf{U}}{\partial m}\right),
\end{aligned}
$$

where $\mathbf{c}_{g}$ is the group velocity of waves, $\mathbf{U}$ is the ocean surface current vector, $\mathbf{k}$ is the wavenumber vector, $s$ is a coordinate in the direction $\theta$, and $m$ is a coordinate perpendicular to $s$. The left-hand side (lhs) of Eq. (3) represents the local rate of change of the action density (the first term) and the wave propagation 


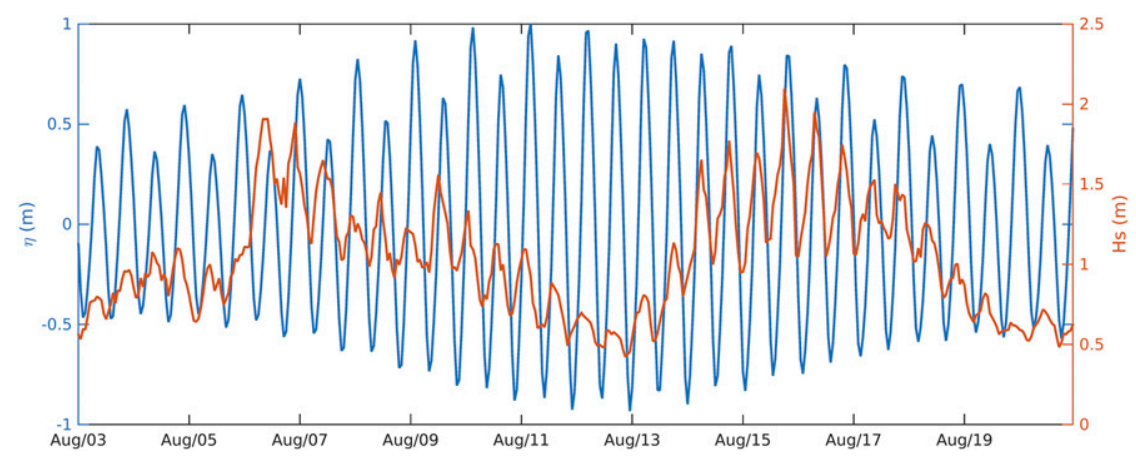

FIG. 5. Time series of predicted tidal elevation (blue) with superimposed time series of observed significant wave height (red) on 3-19 Aug 2010.

in spatial (second term) and spectral (third and fourth terms) space. The right-hand side (rhs) of Eq. (3) contains the net source term $S_{\text {tot }}$, which includes all physical processes that generate, dissipate, and redistribute the wave energy. The significant wave height can be derived by integrating the variance spectrum:

$$
H_{s}=4 \sqrt{E}, \quad E=\iint F(k, \theta) d k d \theta .
$$

The lhs of Eq. (3) indicates that ocean circulation affects wave propagation in three ways. First, the horizontal variation of ocean currents causes the convergence of wave-action flux in the spatial space. Second, in the spectral space, the horizontal variation of ocean currents causes wavenumber shift ("concertina effect") and wave refraction in the way similar to effects of the bathymetry variation. Third, the sea surface elevation modifies the total water depth used in the wave model, although this effect is only large in the very shallow water regions where waves could feel the ocean bottom. On the rhs of Eq. (3), ocean circulation affects the wave-action density spectrum through wave growth and dissipation. For the wave growth, the surface wind vector $\mathbf{U}_{10}$ used to calculate the wave growth is replaced by $\mathbf{U}_{10}-\alpha \mathbf{U}$. Here $\alpha=0.7$ (Wang and Sheng 2016) is a tuning coefficient for the relative wind effect in WW3. The effects of currents on whitecapping dissipation $S_{\mathrm{ds}}$ is implicitly implemented in WW3, and the parameterization of $S_{\mathrm{ds}}$ (see the appendix) used in this study is based on the Babanin-Young-DonelanRogers-Zieger (BYDRZ) source-term package known as "ST6" (Tolman et al. 2014).

WW3 uses the same horizontal model grid and bathymetry as DalCoast. To account for the effect of swells generated outside of the study area, a coarser-resolution wave model that is based also on WW3 is applied to a larger domain of $84^{\circ}-10^{\circ} \mathrm{W}$ and $10^{\circ}-65^{\circ} \mathrm{N}$ with a horizontal resolution of $1 / 4^{\circ}$. The wave model results over this larger domain are used to provide boundary conditions for the wave model of the eastern Canadian shelf. The spectral domain consists of 36 directional bins with $10^{\circ}$ of resolution and 29 frequencies $f_{n}$ ranging from 0.04 to $0.6 \mathrm{~Hz}$ with a logarithmic increment of $f_{n+1}=1.1 f_{n}$. The ST6 package (Tolman et al. 2014) is applied to compute the wave growth and dissipation source terms.

\section{c. Design of numerical experiments}

Two basic numerical experiments (Table 2) were conducted to examine the effects of tidal currents on ocean waves in the GoM, which include the coupled wave-circulation model run (Run_WaveCir, control run) and the wave-only model run (Run_WaveOnly). Furthermore, four additional process-oriented experiments were conducted to quantify major mechanisms that affect the ocean waves in the study region. Four specific WCI mechanisms are considered in this study, which include 1) the relative wind effect, 2) currentinduced convergence, 3 ) current-induced wavenumber shift, and 4) current-induced refraction. Model configurations and model forcing for six numerical experiments are summarized in Table 2.

\section{Comparison with observational data}

The performance of the coupled model in simulating the tidal elevations and currents in the GoM has been found to be reasonable through a comparison of model results with the OTIS tidal solutions and ADCP measurements (not shown). The focus in this section is on the performance of the coupled model in simulating the surface waves in the GoM based on the model results in the control run (Run_WaveCir). To quantify the model performance, we follow Thompson and Sheng (1997) and use $\gamma^{2}$, which is defined as the ratio of the hindcast error variance to the observed variance: 
TABLE 2. Model configurations for six numerical experiments $\left(\mathbf{U}_{10}\right.$ is the $10-\mathrm{m}$ wind velocity vector, $\mathbf{U}$ is the ocean surface current vector, $\alpha$ is a tuning coefficient, $\mathbf{k}$ is the wavenumber vector, $s$ is a coordinate in the direction of wave propagation, and $m$ is a coordinate perpendicular to $s$ ).

\begin{tabular}{lcccc}
\hline \hline \multicolumn{1}{c}{ Expt } & $\begin{array}{c}\text { Relative wind effect } \alpha \mathbf{U} \\
\text { in the term of }\left(\mathbf{U}_{10}-\alpha \mathbf{U}\right)\end{array}$ & $\begin{array}{c}\text { Current-induced wave } \\
\text { convergence } \mathbf{U} \text { in Eq. (4) }\end{array}$ & $\begin{array}{c}\text { Current-induced } k \text { shift } \\
\mathbf{k} \cdot(\partial \mathbf{U} / \partial s) \text { in Eq. (5) }\end{array}$ & $\begin{array}{c}\text { Current-induced wave refraction } \\
\mathbf{k} \cdot(\partial \mathbf{U} / \partial m) \text { in Eq. (6) }\end{array}$ \\
\hline Run_WaveCir & On & On & On & On \\
Run_WaveOnly $_{\text {Run_WaveU } 10}$ & Off & Off & Off & Off \\
Run_WaveC $_{\text {g }}$ & On & Off & Off & Off \\
Run_Wavek & Off & On & Off & Off \\
Run_Wave $\theta$ & Off & Off & On & Off \\
\hline
\end{tabular}

$$
\gamma^{2}=\operatorname{Var}(O-M) / \operatorname{Var}(O)
$$

where Var represents the variance and $O$ and $M$ denote respectively the observed and simulated time series of a variable. A smaller value of $\gamma^{2}$ denotes a better agreement between the observed and simulated values. Values of $\gamma^{2}$ of less than unity indicate that the observed variance is reduced by the subtraction of the hindcasts from the observations. Values of $\gamma^{2}$ that are greater than or equal to unity can occur if the model is deficient in some important way or the observations are dominated by measurement noises. In this study, we use $\gamma^{2}=1$ as a threshold to assess the model performance.

Figure 6 presents time series of observed and simulated mean wave variables at buoy 44018. The waveonly model (Run_WaveOnly) reproduces reasonably well the observed subtidal variations of surface waves, with relatively low values of $\gamma^{2}$ for the $H_{s}(0.19), T_{p}$ (0.66), and $\theta_{m}(1.02)$ at buoy 44018 . The wave-only model, however, does not reproduce the observed tidal modulations at this buoy. The coupled model (Run_WaveCir, control run), by comparison, successfully reproduces the observed semidiurnal oscillation in the surface waves with smaller values of $\gamma^{2}$ for all mean wave variables (Table 3 ). The modelobservation comparisons at the other three buoys (buoys 44005, 44008, 44027) yield the same conclusion as at 44018 . The $\gamma^{2}$ values at the four buoys are listed in Table 3.

Figure 7 presents observed and simulated power spectra of $H_{s}$ at the four wave buoys. As expected, the model results in Run_WaveOnly do not have the observed semidiurnal spectral peak at these four buoys. By comparison, the model results in Run_WaveCir reproduce very well the observed semidiurnal peak at four buoys in the two months. It is noted that some of the observed spectra (Figs. 7d,f,g) have spectral peaks between diurnal and semidiurnal frequencies, which were not captured by the two model runs. The similar corresponding peaks were also found in the observed wind speed spectra but not in the spectra of local winds used by the model (not shown). Thus, the abovementioned discrepancy is largely due to the deficiency in reanalysis winds used by the model.

Figure 8 presents observed and simulated directional wave spectra at buoy 44018 at four tidal phases that are maximum ebb at 1000 , slack tide at 1300 , maximum flood at 1600, and slack tide at 1900 UTC 14 August 2010. The corresponding observed and simulated frequency-dependent mean wave direction and directional spread at these four tidal phases are also presented in Fig. 9. The observed directional spectra are relatively broad with large wave energy coming from northeastsoutheast directions with frequencies of $0.10-0.15 \mathrm{~Hz}$. From the maximum ebb to the second slack tide, the dominant wave directions first turned to the southeast and then turned to the east, and the dominant wave frequencies first moved to higher frequencies and then moved slightly to lower frequencies. In comparison, the coupled model (Run_WaveCir) reproduces reasonably well the observed movements of the spectrum in the directional-frequency space induced by tidal currents, which are completely missed in Run_WaveOnly. However, the simulated spectra provided by both model runs are relatively narrow, and the mean directional spread is underestimated by $8^{\circ}-30^{\circ}$ at frequencies of $0.10-0.15 \mathrm{~Hz}$ (Figs. 9e-h). This is not surprising, because the wave models commonly used in the community are not well designed to simulate the directional wave spectrum. Nevertheless, the inclusion of tidal currents is found to be able to improve the simulated directional spread by $\sim 4^{\circ}$ at frequencies of $0.10-0.15 \mathrm{~Hz}$ during the ebb tide (Figs. 9e,f).

\section{Process-oriented studies}

The numerical model results in six numerical experiments listed in Table 2 (including the control run, waveonly model run, and four process-oriented model runs) 

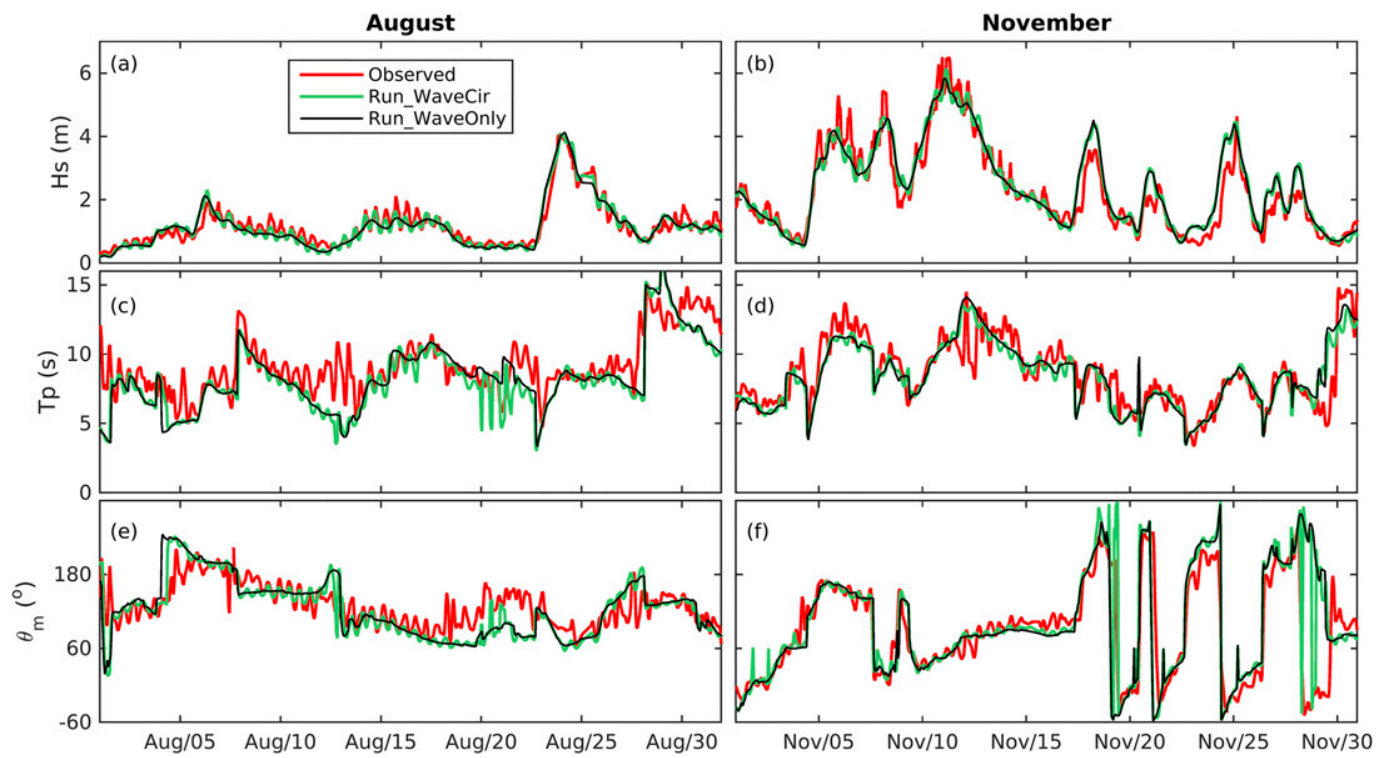

FIG. 6. Time series of observed (red) and simulated (green and black) (a),(b) significant wave heights; (c),(d) peak wave periods; and (e),(f) mean wave directions at buoy 44018 in (left) August and (right) November 2010.

are used in this section to examine the major WCI mechanisms controlling the tidal modulations of surface waves in the GoM. Figure 10 presents time series of simulated mean wave variables at buoy 44018 on 10-17 August 2010 in five different runs. Three major controlling mechanisms are identified for the tidal modulation in $H_{s}$ (Fig. 10a): current-induced convergence, refraction, and wavenumber shift. The modulations of $H_{s}$ induced by the three mechanisms, however, have different amplitudes and phases relative to overall $H_{s}$ modulation in the control run. Another interesting feature is that the $H_{s}$ modulation induced by the refraction has noticeable temporal changes from 10-13 August to 14-17 August with respect to those in the control run. It is noted that during this period the mean wave directions change approximately from the south $\left(140^{\circ}-160^{\circ}\right)$ to the east $\left(60^{\circ}-100^{\circ}\right)$. This indicates that the refraction-induced $H_{s}$ modulation can be strongly affected by the wave propagation direction. The mechanisms controlling the tidal modulations in $T_{p}$ and $\theta_{m}$ are less complex than those in $H_{s}$. A comparison of model results in different runs (Figs. 10b,c) demonstrates that the modulation in $T_{p}$ is mainly due to the wavenumber shift as expected in Eq. (5), and the modulation in $\theta_{m}$ is mainly due to refraction as expected in Eq. (6). It should be mentioned that the relative wind effect is small in this case for swell-dominated waves (not shown). Model results during other periods yield the same conclusion at this buoy location, but contributions of different mechanisms to the tidal modulation in $H_{s}$ differ over different areas in the GoM as we will show later.

Figure 11 presents distributions of amplitudes of tidal modulations in $H_{s}$ in August 2010. The amplitude is calculated as the square root of the differences in semidiurnal $H_{s}$ variance between Run_WaveCir

TABLE 3. Values of $\gamma^{2}$ for wave variables $H_{s}, T_{p}$, and $\theta$ in two different model runs (Run_WaveCir and Run_WaveOnly) at four wave buoy stations in August and November 2010. Here, N/A means values are not available.

\begin{tabular}{|c|c|c|c|c|c|c|c|c|c|c|}
\hline \multirow[b]{2}{*}{ Model run } & \multicolumn{3}{|c|}{44018} & \multicolumn{3}{|c|}{44008} & \multicolumn{2}{|c|}{44005} & \multicolumn{2}{|c|}{44027} \\
\hline & $H_{s}$ & $T_{p}$ & $\theta$ & $H_{s}$ & $T_{p}$ & $\theta$ & $H_{s}$ & $T_{p}$ & $H_{s}$ & $T_{p}$ \\
\hline \multicolumn{11}{|c|}{ August } \\
\hline Run_WaveCir & 0.13 & 0.62 & 0.90 & 0.12 & 0.42 & 0.47 & 0.20 & 0.61 & 0.28 & 0.58 \\
\hline Run_WaveOnly & 0.19 & 0.66 & 1.02 & 0.14 & 0.44 & 0.51 & 0.21 & 0.66 & 0.29 & 0.62 \\
\hline \multicolumn{11}{|c|}{ November } \\
\hline Run_WaveCir & 0.09 & 0.32 & 0.63 & 0.09 & 0.25 & 0.56 & 0.07 & 0.39 & N/A & N/A \\
\hline Run_WaveOnly & 0.11 & 0.36 & 0.71 & 0.10 & 0.27 & 0.62 & 0.08 & 0.40 & N/A & N/A \\
\hline
\end{tabular}




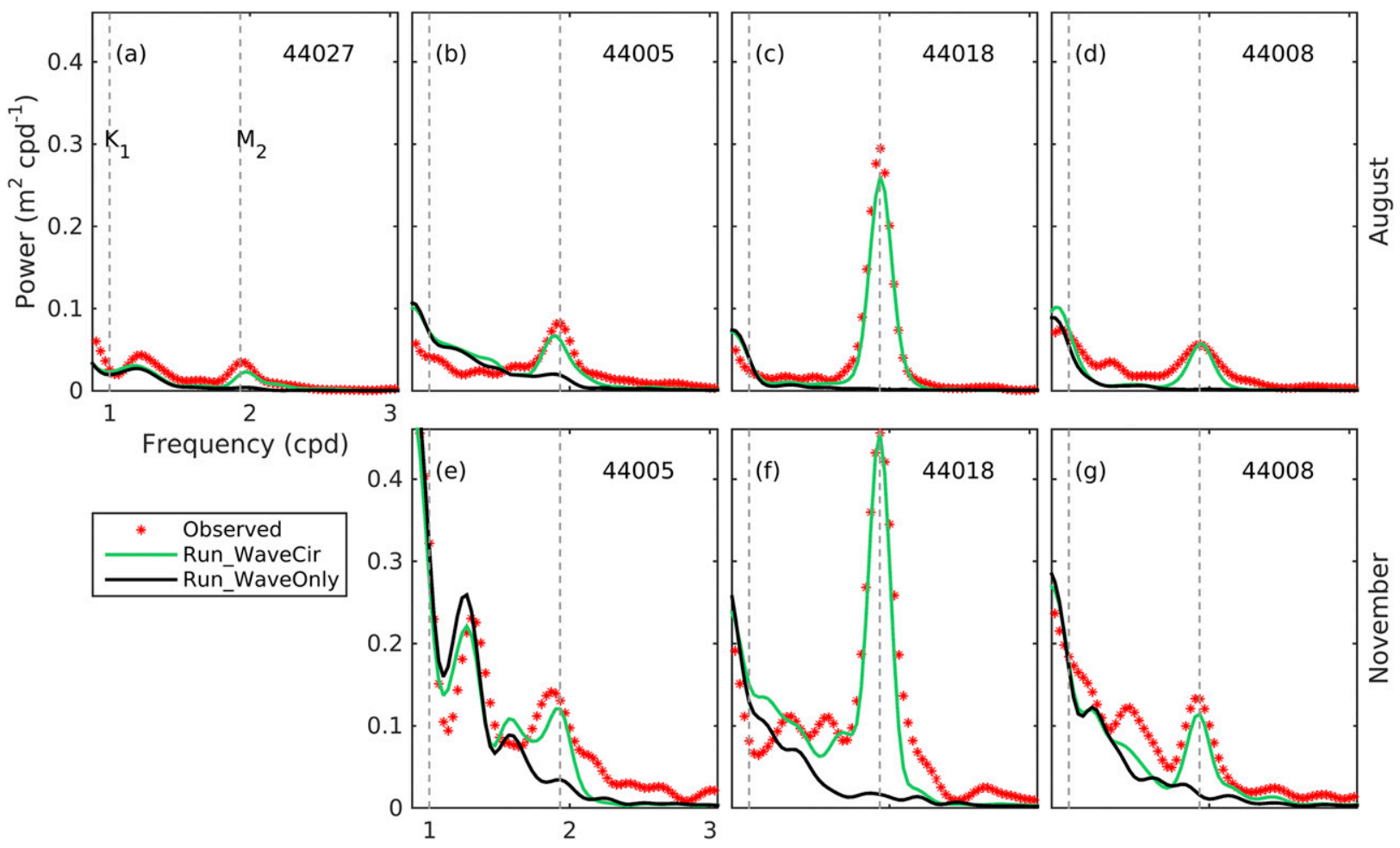

FIG. 7. Observed (red) and simulated (green and black) power spectra of the wave height time series at different wave buoy sites in (a)-(d) August and (e)-(g) November 2010.

(or process-oriented model runs) and Run_WaveOnly. The semidiurnal $H_{s}$ variance is defined as the integral of the spectrum between two cutoff frequencies of the semidiurnal peak. Figure 11a shows that the amplitude in the control run reaches its maximum over areas just behind GB where buoy 44018 was located, and decreases toward the inner gulf. The amplitude is also relatively large over the southern flank of GB and near the west coast of Nova Scotia where there are strong current gradients. By comparison, the amplitude is relatively small on GB where the tidal currents are strongest. Process-oriented experiments demonstrate that the current-induced convergence (Fig. 11b) mainly contributes to the $H_{s}$ modulation over the northern and southern flanks of GB. The distribution of amplitude due to wavenumber shift (Fig. 11c) is similar to that due to convergence, except for smaller magnitudes. Different from the other two mechanisms, the refraction effect (Fig. 11d) mainly contributes to the $H_{s}$ modulation on GB and over areas just behind GB.

We next investigate how the three major controlling WCI mechanisms contribute to the tidal modulation of $H_{s}$ by examining distributions of percentage changes in $H_{s}$ between three process-oriented model runs and Run_WaveOnly in two special events with northward (event A; Figs. 12a,b) and westward (event B; Figs. 12c,d) propagating surface waves, respectively.

\section{a. Current-induced convergence}

The current-induced convergence modulates the significant wave height $H_{s}$ by modifying the propagation velocity vector of surface wave energy [see Eq. (4)], and its effect depends on the spatial gradients of currents. During event A at the maximum flood (Fig. 12e), the model results associated with this mechanism show significant wave-energy convergence (up to $14 \%$ ) over the northern flank of GB and near the west coast of Nova Scotia and noticeable energy divergence over the southern flank of GB. These energy convergence (divergence) zones are associated with strong spatially decelerating (accelerating) tidal currents. The convergence effect for this event is similar to the depth-induced wave shoaling, with surface waves and currents propagating nearly in the same direction. If directions of waves and currents are different (e.g., event B), the convergence effect can also change the propagation direction of wave energy, which is thus similar to the refraction effect. Figure $12 \mathrm{~g}$ shows the result during event $\mathrm{B}$ at the maximum flood is very similar to that during event $\mathrm{A}$, indicating that the convergence effect is less 


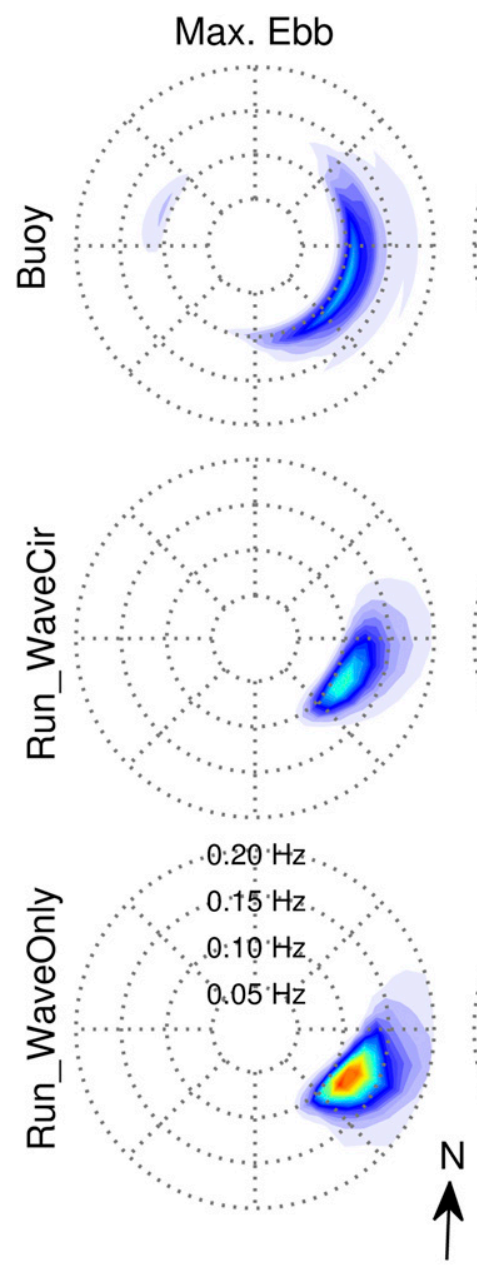

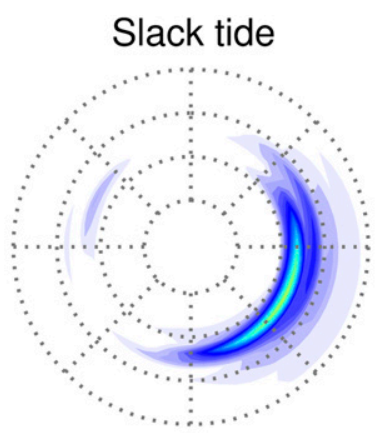
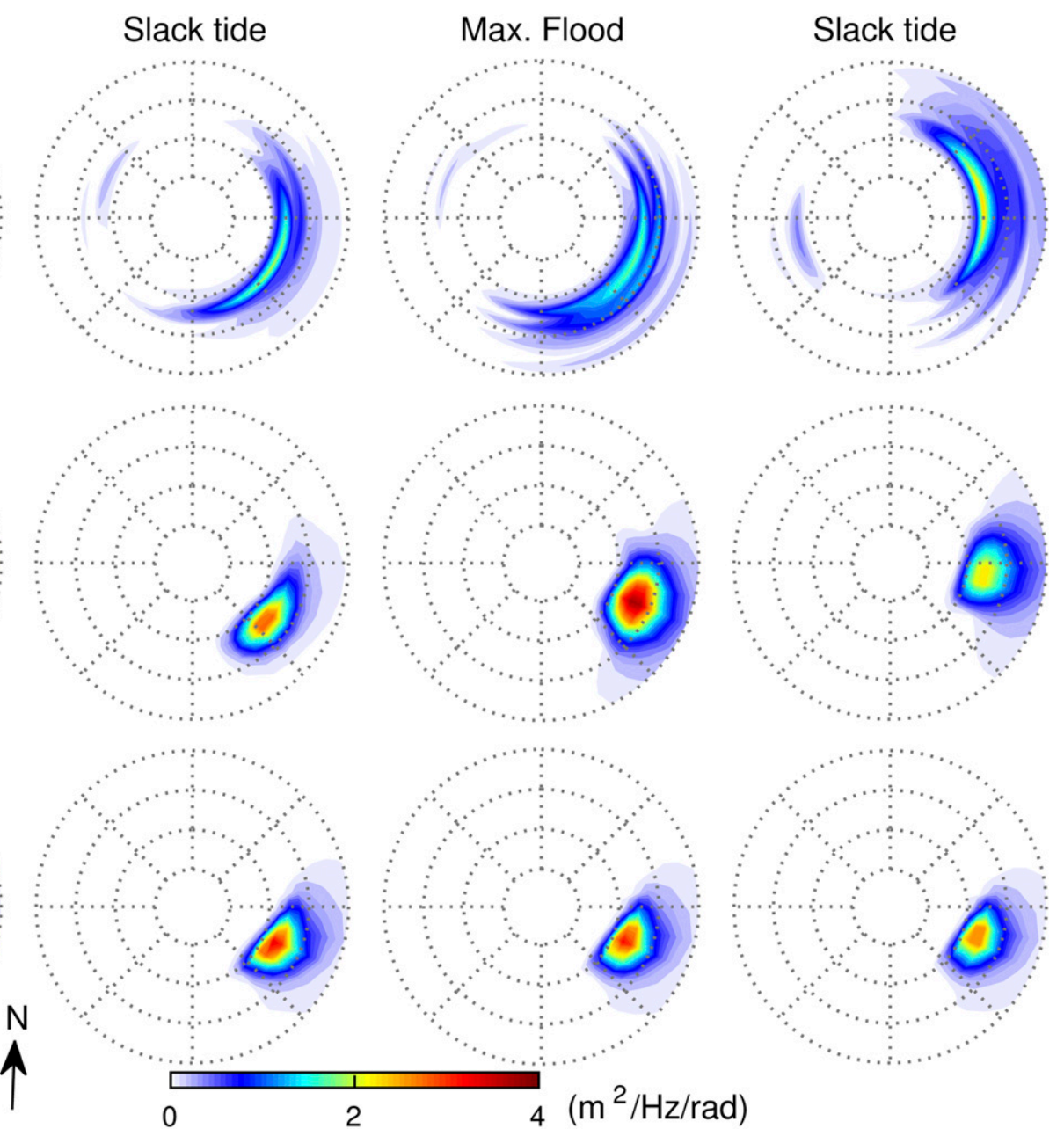

FIG. 8. (top) Observed and (middle),(bottom) simulated directional wave spectra at four typical tidal phases at buoy 44018 on 14 Aug 2010. The color scales represent spectral density, and the dashed circles correspond to frequencies of $0.05,0.10,0.15$, and $0.20 \mathrm{~Hz}$. Wave directions are defined using the meteorological convention that "N" means "coming from north."

affected by the wave propagation direction and is mainly determined by the spatial structure of currents.

Three hours later (i.e., slack tide), the model results for events A and B (Figs. 12f,h) respectively show northward and westward propagations of the tidal modulation in $H_{s}$ produced at the maximum flood. The propagation distance is $\sim 50 \mathrm{~km}$, and the estimated speed is $\sim 5 \mathrm{~m} \mathrm{~s}^{-1}$. The latter is comparable to the typical magnitude of $\mathbf{c}_{g}$ for a 6.5 -s period wave over this area. This indicates that during the slack tide the effects of local tidal currents become relatively weak, and the tidal modulation in the gulf is mainly a spatial propagation of that generated during flood tide.

To interpret the model results further, we use analytical results for unidirectional, monochromatic linear waves by ignoring wave generations and dissipations. Considering a deep-water surface wave propagating from a region 1 with currents of magnitude $U_{1}$ to a region 2 with currents of magnitude $U_{2}$, the equality of action fluxes gives

$$
\frac{E_{1}}{\sigma_{1}}\left(C_{g 1}+U_{1}\right)=\frac{E_{2}}{\sigma_{2}}\left(C_{g 2}+U_{2}\right),
$$

which gives the change in $H_{s}$ :

$$
\frac{H_{s 2}}{H_{s 1}}=\left(\frac{E_{2}}{E_{1}}\right)^{1 / 2}=\left(\frac{\sigma_{2}}{\sigma_{1}} \frac{C_{g 1}+U_{1}}{C_{g 2}+U_{2}}\right)^{1 / 2} .
$$

Eq. (10) is identical to that derived by Longuet-Higgins and Stewart (1961) that is based on the wave-energy balance equation in the case with convergence of $\mathbf{U}$ balanced vertically. Longuet-Higgins and Stewart (1961) also considered a second case with the convergence of 


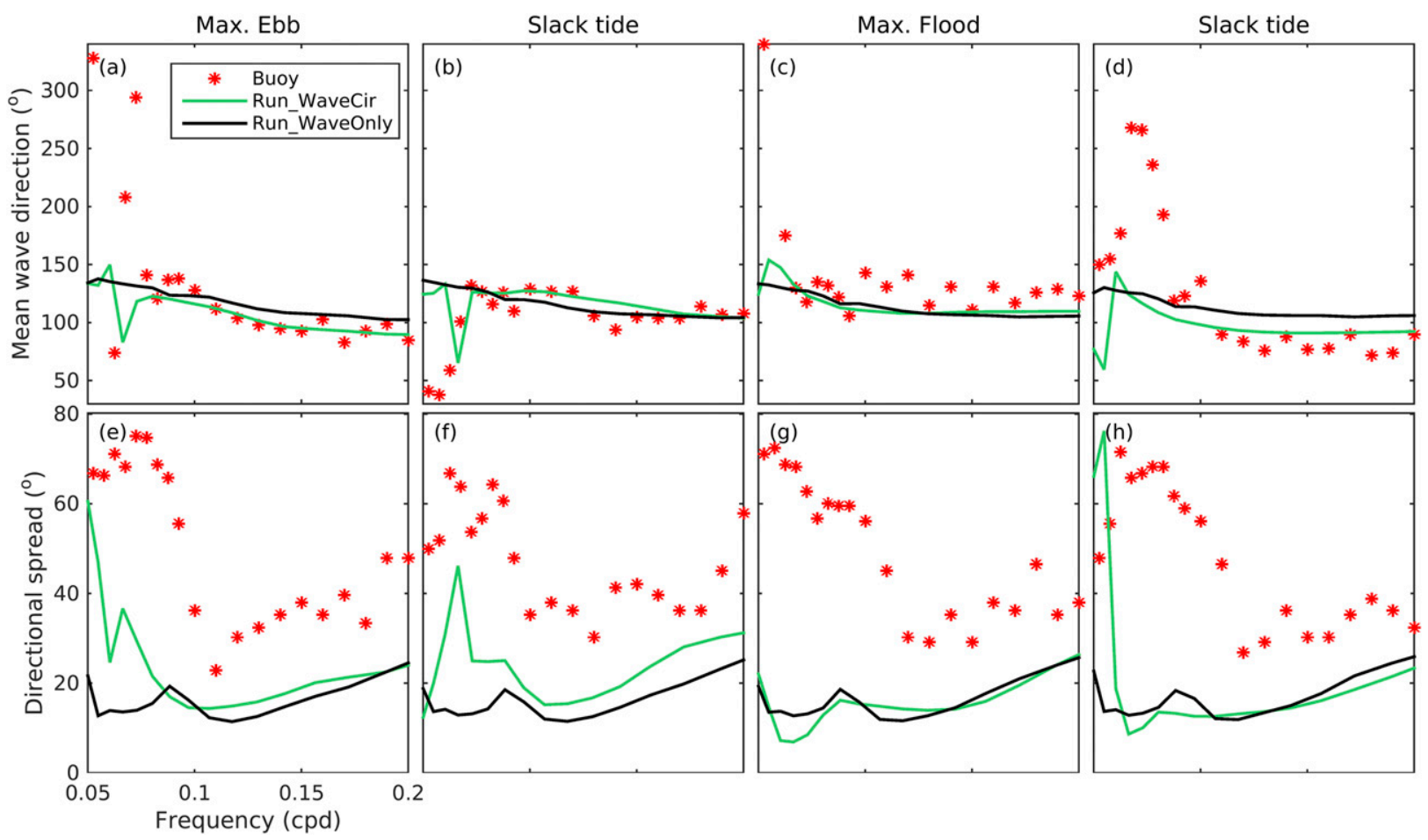

FIG. 9. Observed and simulated (a)-(d) frequency-dependent mean wave direction and (e)-(h) directional spread at four typical tidal phases at buoy 44018 on 14 Aug 2010.

$\mathbf{U}$ balanced laterally and showed that the solution is Eq. (10) multiplied by a factor of $C_{g 2} / C_{g 1}$. In this study, since the major current gradients occur approximately in the north-south direction over GB and the lateral variation of tidal currents is relatively small, we can use Eq. (10) to illustrate our model results. It is noted that the changes in $\sigma$ and $C_{g}$ in Eq. (10) are due to the currentinduced wavenumber shift, as we will discuss later. Considering only the convergence effect (i.e., $\sigma_{2}=\sigma_{1}$ and $C_{g 2}=C_{g 1}$ ), Eq. (10) gives a factor of

$$
\left(\frac{C_{g 1}+U_{1}}{C_{g 1}+U_{2}}\right)^{1 / 2} .
$$

Considering a 6.5 -s period wave $\left(C_{g 1} \approx 5 \mathrm{~m} \mathrm{~s}^{-1}\right)$ propagating from $\mathrm{GB}\left(U_{1} \approx 1 \mathrm{~m} \mathrm{~s}^{-1}\right)$ to the area behind $\mathrm{GB}$ (similar to event $\mathrm{A}$ at the maximum flood, $U_{2} \approx 0 \mathrm{~m} \mathrm{~s}^{-1}$ ), the estimated percentage change in $H_{s}$ is approximately $10 \%$, which explains most of those $(10 \%-14 \%)$ produced by the model over the northern flank of GB (Fig. 12e). The differences between the above theoretical estimates and the model results can be due to the unsteadiness of tidal currents. For example, the typical propagation time of surface waves over GB is about $5.5 \mathrm{~h}$, which is not small in comparison with the period of $\mathrm{M}_{2}$ tidal currents $(\sim 12.4 \mathrm{~h})$. Thus, surface waves propagating across GB are subject to subsequent modulations by different current fields at different tidal phases. However, since most of the $H_{s}$ modulation can be explained by the solution in the steady situation, the time dependence of tidal currents is expected to play a minor role in the tidal modulation over this region.

\section{b. Current-induced wavenumber shift}

The effect of current-induced wavenumber shift depends on the spatial gradients of currents in the propagation directions of surface waves [see Eq. (5)]. Since the current-induced wavenumber shift induces change in $\dot{k}$ that is associated with a change in $\sigma$ and $\mathbf{c}_{g}$, it can modify $H_{s}$ through two processes (Ardhuin et al. 2017): an exchange of energy between waves and currents (i.e., the radiation stress effect) due to the change in $\sigma$, and energy bunching/stretching (similar to wave shoaling) due to the change in $\mathbf{c}_{g}$. The effects of both processes decrease (increase) $H_{s}$ for the case of waves propagating into accelerating (decelerating) currents. During event A, the model results at the two tidal phases (Figs. 12i,j) show a clear northward propagation of tidal modulations in $H_{s}$. The maximum tidal modulation is generated over the northern/southern flanks of GB at the maximum flood because of strong tidal current gradients in the north-south direction. By comparison, the model 


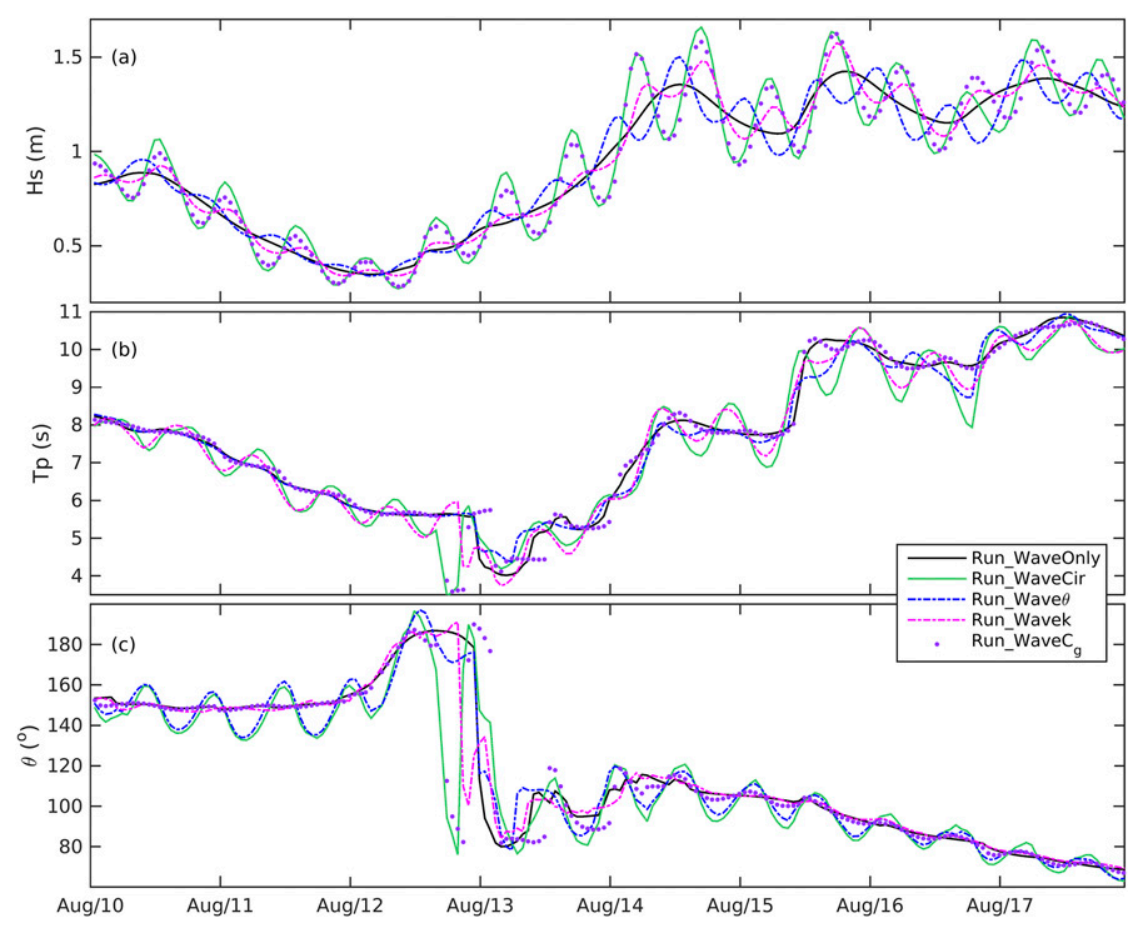

FIG. 10. Time series of (a) significant wave heights, (b) peak periods, and (c) mean wave directions at buoy 44018 on 10-17 Aug 2010 in five different numerical experiments.

results during event $\mathrm{B}$ (Figs. 12k,l) show an eastward propagation of tidal modulations, with noticeable increases of $H_{s}$ generated around the mouth of the GoM at the maximum flood because of strong tidal current gradients in the east-west direction. Thus, different from the convergence effect, the current-induced wavenumber shift varies with the wave propagation direction. In particular, in the case of surface waves traveling perpendicular to the direction of tidal currents over GB at the maximum flood, model results show that the effect of the current-induced wavenumber shift becomes negligible (not shown).

We also use the analytical results in section 5a to interpret the model results. From Eq. (10), the factor for the change in $H_{s}$ due to wavenumber shift is

$$
\left(\frac{\sigma_{2}}{\sigma_{1}} \frac{C_{g 1}}{C_{g 2}}\right)^{1 / 2},
$$

which is approximately equal to $\sigma_{2} / \sigma_{1}$ given $C_{g}=g /(2 \sigma)$. The solution is found to be $\sigma_{2} / \sigma_{1}=\left[1+U_{1} /\left(2 C_{g 1}\right)\right]$ (F. Ardhuin 2018, personal communication; see also http:// doi.org/10.13140/RG.2.2.16019.78888/2) on the basis of conservation of the number of wave crests. Using the same example discussed in section $5 \mathrm{a}\left(C_{g 1} \approx 5 \mathrm{~m} \mathrm{~s}^{-1} ; U_{1}\right.$ $\approx 1 \mathrm{~m} \mathrm{~s}^{-1}$ ), the estimated percentage change in $H_{s}$ due to the wavenumber shift is $\sim 10 \%$, which is similar to those
$(8 \%-10 \%)$ produced by the model over the northern flank of GB during event A (Fig. 12i). Thus, the tidal modulation in $H_{s}$ due to the wavenumber shift is mostly explained by the spatial variation of currents.

\section{c. Current-induced refraction effect}

The current-induced refraction effect depends on the gradients of currents along the wave crest direction [see Eq. (6)]. The basic effect of this mechanism is to turn surface waves toward the area with lower absolute propagation speeds (i.e., relative to the fixed bottom) and causes wave-energy focusing and defocusing. Thus, during event $\mathrm{A}$ at the maximum flood (Fig. $12 \mathrm{~m}$ ), surface waves propagating over GB are refracted to the east and west parts of GB associated with the lower tidal current speeds. While during event B (Fig. 12o), surface waves are refracted to the north and south sides of $\mathrm{GB}$, resulting in significant defocusing of wave energy (up to $20 \%$ in $H_{s}$ ) on GB and noticeable focusing of wave energy $(\sim 14 \%$ in $H_{s}$ ) over areas behind GB. Note that the current-induced refraction effect is much more significant for event $B$ than event $\mathrm{A}$, because the tidal current gradients in the northsouth direction are much larger than those in the eastwest direction around GB. Similar to the other two mechanisms, the refraction-induced $H_{s}$ modulation during the slack tide (Figs. $12 \mathrm{n}, \mathrm{p}$ ) is mainly a spatial propagation of that generated during flood tide (Figs. 12m,o). 

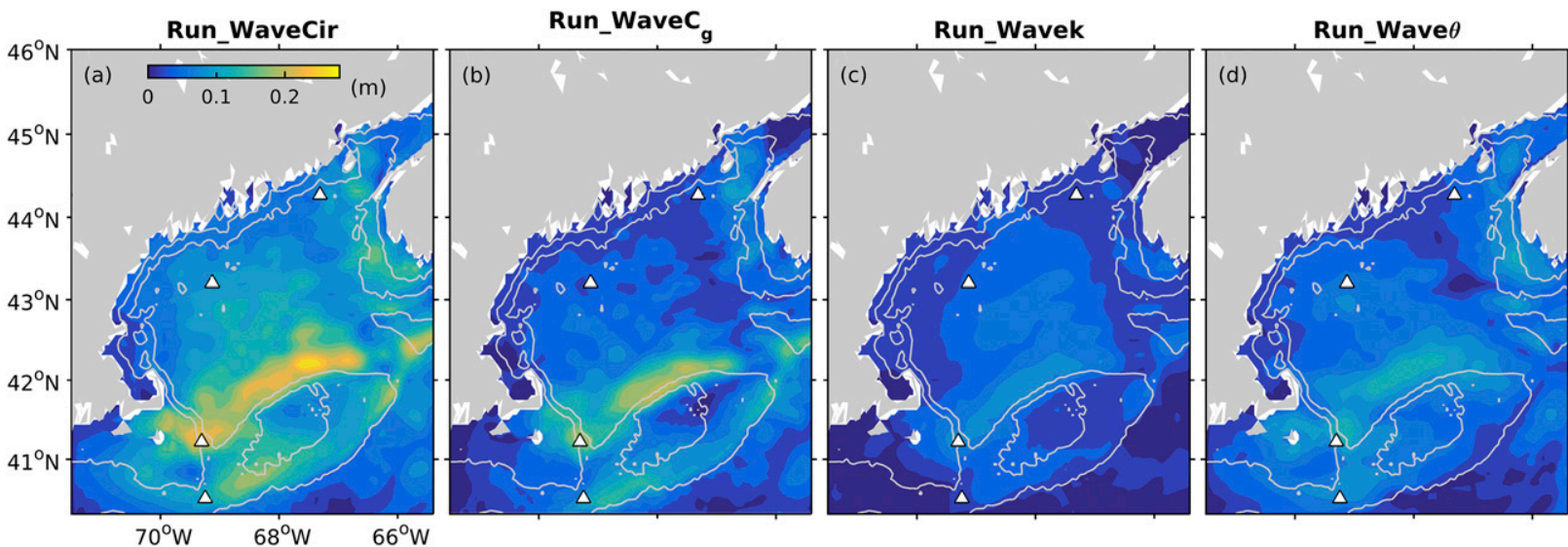

FIG. 11. Amplitudes of semidiurnal tidal modulations in significant wave heights in four different numerical experiments in August 2010. The contour lines indicate the $50-$ and $100-\mathrm{m}$ isobaths. The triangles denote wave buoy locations.

Overall, the above analyses demonstrate that the significant effects of all three current-induced mechanisms depend on the strong gradients of tidal currents near the mouth of the GoM, particularly around GB. Furthermore, the modulations of $H_{s}$ due to convergence are less affected by the wave propagation direction, while those due to wavenumber shift and refraction vary with the changes in wave propagation direction. Therefore, the distribution of tidal modulation in $H_{s}$ over the GoM is not fixed in time and space. The combined effects of all three mechanisms in the tidal modulation (Figs. 12q- $\mathrm{t}$ ) could reach $25 \%$ over areas behind GB. In addition, the above analyses also demonstrated that the observed maximum $H_{s}$ modulation during the flood tide (i.e., in the following tidal currents) at buoy 44018 can be mostly explained by the tidal-current-induced convergence and wavenumber shift associated with wave-energy convergence and energy transfer from tidal currents to surface waves in spatially decelerating tidal currents (e.g., Figs. 12e,i,g,k). Although the refraction effect also contributes the overall $H_{s}$ modulation at this particular location, this effect does not significantly change its phase because of the dominant effects of the other two mechanisms.

\section{d. Current-enhanced wave dissipation}

The effects of current-enhanced wave dissipation on the tidal modulation of $H_{s}$ is not easily separated from other mechanisms, since the current-enhanced wave dissipation is implicitly implemented in the model (see the appendix). For simplicity of discussion, we consider time series of the calculated wave dissipation term $S_{\mathrm{ds}}$ in Run_WaveOnly and Run_WaveCir at buoy 44018 in the second half of August 2010, shown in Fig. 13a. Wave dissipation is shown to be only significant around 23 August during a strong wind event. In comparison with Run_WaveOnly, model results in Run_WaveCir demonstrate a significant tidal modulation of $S_{\mathrm{ds}}$ around 23 August, which correlates with the tidal modulation of $H_{s}$ (Fig. 13a). Furthermore, distributions of differences in wave dissipation $\Delta S_{\mathrm{ds}}$ between Run_WaveCir and Run_WaveOnly at two selected maximum floods also correlate with those of $\Delta H_{s}$ (cf. Fig. 13b with Fig. 13c and Fig. 13d with Fig. 13e), particularly over areas behind GB. The correlation of $\Delta S_{\mathrm{ds}}$ with $\Delta H_{s}$ in both space and time suggests that the current-enhanced dissipation could reduce the magnitudes of $H_{s}$ modulation during this strong wind event.

To estimate how much of the tidal modulation in $H_{s}$ is reduced by the current-enhanced dissipation, we compare the model results between two selected maximum flood tides. Figures $13 \mathrm{~b}$ and $13 \mathrm{~d}$ show that the current-enhanced dissipation $\Delta S_{\mathrm{ds}}$ over areas behind GB at the first flood is much more significant than that at the second flood. As a result, the magnitudes of increased $H_{s}\left(\Delta H_{s}\right)$ over areas behind GB at the first flood are only about one-half of those at the second flood (Figs. 13c,e). This indicates that at least half of the tidal modulation in $H_{s}$ is eliminated by the current-enhanced dissipation at the first flood.

\section{Summary and conclusions}

This study examined the tidal modulation of surface gravity waves in the Gulf of Maine (GoM) based on in situ observations and numerical model results produced by a coupled wave-circulation model. Analysis of observational data demonstrated significant semidiurnal tidal modulations in the mean surface wave variables (i.e., significant wave height $H_{s}$, peak wave period $T_{p}$, and mean wave direction $\theta_{m}$ ) in the study region. The amplitudes of tidal modulations in $H_{s}, T_{p}$, and $\theta_{m}$ can 

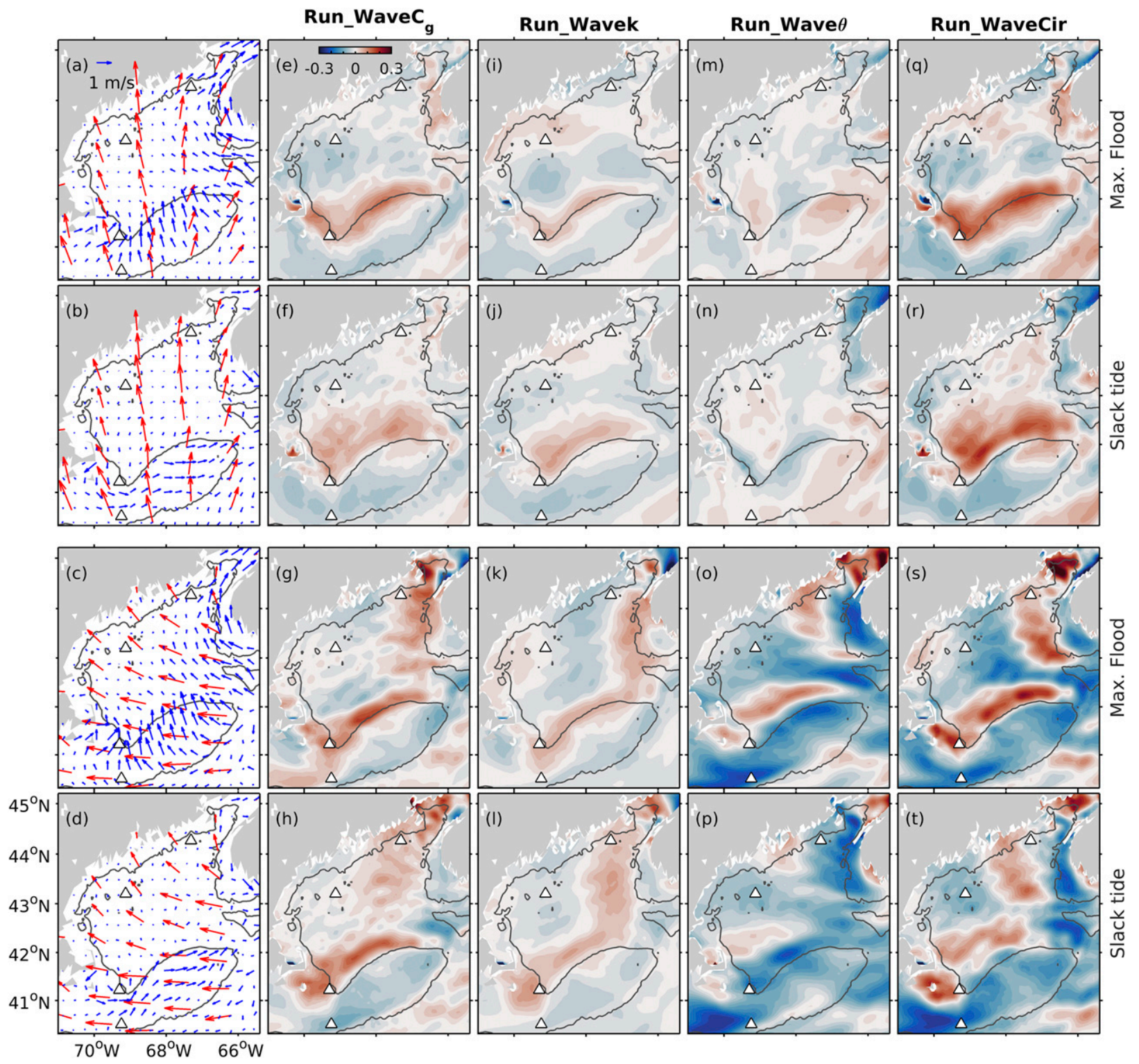

FIG. 12. The ocean surface current vectors (blue arrows) and surface wave vectors (the length and direction of the wave vectors represent the mean wavelength and direction, respectively; red arrows) produced by Run_WaveCir at (a),(c) the maximum flood and (b),(d) subsequent slack tide (top),(top middle)during event A with the northward-propagating waves and (bottom middle),(bottom) during event B with eastward-propagating waves. Differences (image) in significant wave heights (e)-(h) between Run_WaveC $\mathrm{g}_{\mathrm{g}}$ and Run_WaveOnly, (i)-(l) between Run_Wavek and Run_WaveOnly, (m)-(p) between Run_Wave $\theta$ and Run_WaveOnly, and (q)-(t) between Run_WaveCir and Run_ WaveOnly at the maximum flood and subsequent slack tide during two events with northward-propagating (top),(top middle) and (bottom middle),(bottom) eastward-propagating waves. The contour lines indicate the 100-m isobaths, and the triangles denote wave buoy locations.

reach about $0.5 \mathrm{~m}, 3.0 \mathrm{~s}$, and $25^{\circ}$, respectively. The observed tidal modulation features significant spatialtemporal variabilities, with large amplitudes near the mouth of the GoM, particularly during high sea states. The favorable conditions for tidal modulations in the region were found to be swell-dominated surface waves associated with relatively stable wave propagation directions. In addition, the phase relation between tide and $H_{s}$ demonstrates an unusual timing of the maximum $H_{s}$ modulation in the following tidal currents at buoy 44108, located behind Georges Bank (GB).

The coupled wave-circulation model successfully reproduces the observed tidal modulation and associated spatial-temporal variabilities in the GoM. Model results demonstrate that tidal modulations in the GoM are mainly due to the strong horizontal gradients of tidal 

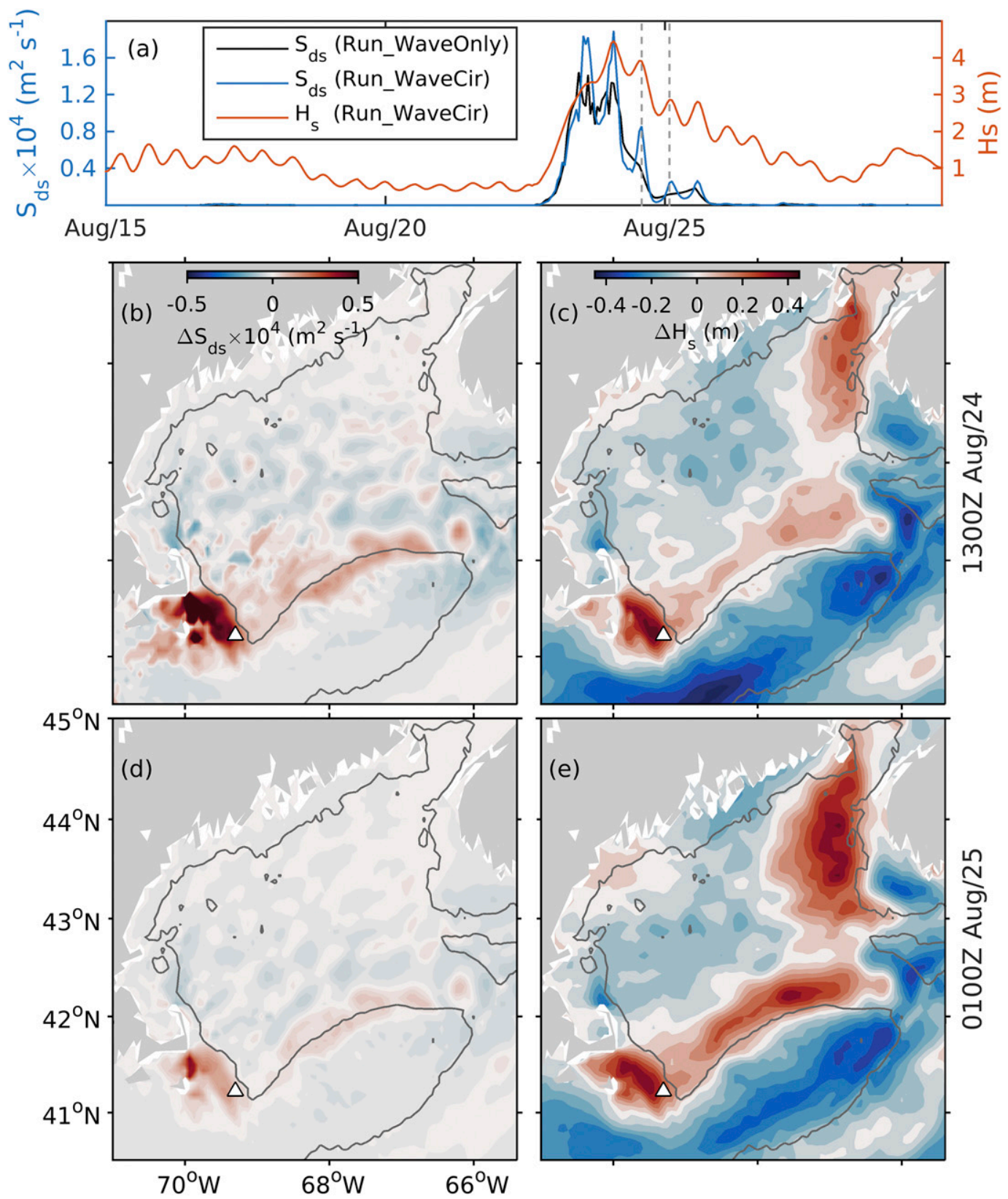

FIG. 13. (a) Time series of simulated wave dissipation $S_{\mathrm{ds}}$ in Run_WaveOnly and Run_WaveCir at buoy 44018, overlaid with time series of simulated $H_{s}$ in Run_WaveCir. Also shown are differences in (b),(d) $S_{\mathrm{ds}}$ and (c),(e) $H_{s}$ between Run_WaveCir and Run_WaveOnly at the two selected maximum flood tides marked by two gray dashed lines in (a). The contour lines in (b)-(e) indicate the 100-m isobaths.

currents near the mouth of the GoM, particularly around GB. The maximum tidal modulations in $H_{S}$ (up to $25 \%$ ) are first generated during the flood/ebb tide when the gradients of tidal currents are strongest and then propagate to the inner gulf. Process-oriented numerical experiments demonstrate that the observed tidal modulation is associated with the current-induced convergence, refraction, and wavenumber shift, which contribute differently to the overall tidal modulation in $H_{s}$ by modifying the propagation velocity vector of surface wave energy, the wavelength, and the wave direction, respectively. The significant effects of all three current-induced mechanisms depend on the strong current gradients near the mouth of the GoM. The tidal modulations of $H_{s}$ due to convergence are less affected by the wave propagation direction and feature relatively 
large effects $(10 \%-14 \%)$ over the northern/southern flanks of GB. By contrast, the tidal modulations of $H_{s}$ due to wavenumber shift $(7 \%-10 \%)$ and refraction $(5 \%-20 \%)$ vary with the changes in the wave propagation direction. Thus, the distribution of overall tidal modulation in $H_{s}$ in the GoM is not fixed in space and time depending on the wave propagation direction. In addition, the currentenhanced dissipation was found to become important during high winds, which could reduce at least one-half of the $H_{s}$ modulation over areas behind GB.

Last, the observed unusual timing of the maximum tidal modulation in $H_{s}$ at buoy 44018 in the following tidal flows can be mostly explained by current-induced convergence and wavenumber shift. This is associated with an energy convergence and an energy transfer from currents to waves in spatially decelerating tidal currents during flood tide.

Acknowledgments. This research was supported in part by the government of Canada program World Class Prevention, Preparedness and Response for Oil Spills from Ships Initiative; the Marine Environmental Observation, Prediction and Response Network (MEOPAR); Ocean Frontier Institute (OFI); and Lloyd's Register (LR). MEOPAR is funded by the government of Canada's Networks of Centers of Excellence Program. The LR helps to protect life and property by supporting engineering-related education, public engagement, and the application of research. Author JS is supported by the Natural Sciences and Engineering Research Council of Canada (NSERC). The authors thank two anonymous reviewers for their constructive comments.

\section{APPENDIX}

\section{The Parameterization for Wave Dissipation}

From the ST6 package in WW3, the whitecapping dissipation term is implemented as

$$
S_{\mathrm{ds}}(k, \theta)=\left[T_{1}(k)+T_{2}(k)\right] N(k, \theta),
$$

where $T_{1}$ is the inherent breaking term accounting for the threshold behavior of wave breaking. The waves do not break unless they exceed a threshold steepness, in which case the wave-breaking probability depends on the level of exceedance above this threshold steepness. The term $T_{2}$ accounts for the cumulative effect of shortwave breaking as a result of longer waves. For example, dissipation rates for short quasi-saturated waves can be modulated by the straining action of longer waves.

The threshold spectral density is defined as $F_{T}(k)=$ $\varepsilon_{T} /\left[A(k) k^{3}\right]$, where $\left(\varepsilon_{T}\right)^{1 / 2}=0.035$ following Babanin et al. (2007) and $A(k) \approx 1$ is the directional narrowness parameter. Let the level of exceedance above the critical threshold spectral density be defined as $\Delta(k)=\max$ $\left[0, F(k)-F_{T}(k)\right]$. Furthermore, let $\mathcal{F}(k)$ be a generic spectral density used for normalization; then the inherent breaking term can be calculated as

$$
T_{1}(k)=a_{1} A(k) \frac{\sigma}{2 \pi}\left[\frac{\Delta(k)}{\mathcal{F}(k)}\right]^{p_{1}} .
$$

The cumulative dissipation term is not local in frequency space and is expressed as an integral that grows toward higher frequencies:

$$
T_{2}(k)=a_{2} \int_{0}^{k} A(k) \frac{c_{g}}{2 \pi}\left[\frac{\Delta(k)}{\mathcal{F}(k)}\right]^{p_{2}} d k
$$

where $a_{1}, a_{2}, p_{1}$, and $p_{2}$ in Eqs. (A2) and (A3) are four coefficients that determine the strength of the dissipation. Equations (A1)-(A3) indicate that the ocean surface currents can indirectly affect the wave dissipation by modifying the wave-action density spectrum $N(k, \theta)$ and the level of exceedance $\Delta(k)$.

\section{REFERENCES}

Ardhuin, F., and Coauthors, 2012: Numerical wave modeling in conditions with strong currents: Dissipation, refraction, and relative wind. J. Phys. Oceanogr., 42, 2101-2120, https://doi.org/ 10.1175/JPO-D-11-0220.1.

- S. T. Gille, D. Menemenlis, C. B. Rocha, N. Rascle, B. Chapron, J. Gula, and J. Molemaker, 2017: Small-scale open ocean currents have large effects on wind wave heights. J. Geophys. Res. Oceans, 122, 4500-4517, https://doi.org/ 10.1002/2016JC012413.

Babanin, A., K. Tsagareli, I. Young, and D. Walker, 2007: Implementation of new experimental input/dissipation terms for modelling spectral evolution of wind waves. Proc. 10th Int. Workshop on Wave Hindcasting and Forecasting, Oahu, HI, WMO, C2, http://www.waveworkshop.org/10thWaves/Papers/ BTYW_2007_10th_Int_Workshop_Wave_Hindcasting_Forecasting a_pdf.

Bennis, A.-C., F. Ardhuin, and F. Dumas, 2011: On the coupling of wave and three-dimensional circulation models: Choice of theoretical framework, practical implementation and adiabatic tests. Ocean Modell., 40, 260-272, https://doi.org/10.1016/ j.ocemod.2011.09.003.

Bigelow, H. B., R. Parmenter, and E. H. Smith, 1927: Physical oceanography of the Gulf of Maine. Bull. U. S. Bur. Fish, 40, 511-1027.

Bolaños, R., J. M. Brown, and A. J. Souza, 2014: Wave-current interactions in a tide dominated estuary. Cont. Shelf Res., 87, 109-123, https://doi.org/10.1016/j.csr.2014.05.009.

Craig, P. D., and M. L. Banner, 1994: Modeling wave-enhanced turbulence in the ocean surface layer. J. Phys. Oceanogr., 24, 2546-2559, https://doi.org/10.1175/1520-0485(1994)024<2546: MWETIT>2.0.CO;2.

Davidson, M. A., T. J. O'Hare, and K. J. George, 2008: Tidal modulation of incident wave heights: Fact or fiction? J. Coastal Res., 2A, 151-159, https://doi.org/10.2112/06-0754.1. 
Egbert, G. D., and S. Y. Erofeeva, 2002: Efficient inverse modeling of barotropic ocean tides. J. Atmos. Oceanic Technol., 19, 183-204, https://doi.org/10.1175/1520-0426(2002)019<0183: EIMOBO $>2.0 . \mathrm{CO} 2$.

Gemmrich, J., and C. Garrett, 2012: The signature of inertial and tidal currents in offshore wave records. J. Phys. Oceanogr., 42, 1051-1056, https://doi.org/10.1175/JPO-D-12-043.1.

Greenberg, D. A., 1983: Modelling the mean barotropic circulation in the Bay of Fundy and Gulf of Maine. J. Phys. Oceanogr., 13, 886-904, https://doi.org/10.1175/1520-0485(1983)013<0886: $\mathrm{MTMBCI}>2.0 . \mathrm{CO} ; 2$

Guillou, N., and G. Chapalain, 2012: Effects of tide on waves in the outer Seine estuary and the harbor of Le Havre. Proc. 33rd Conf. Coastal Engineering, Santander, Spain, International Conference on Coastal Engineering, 47, https://doi.org/10.9753/icce.v33.waves.47.

Hanley, K. E., S. E. Belcher, and P. P. Sullivan, 2010: A global climatology of wind-wave interaction. J. Phys. Oceanogr., 40 1263-1282, https://doi.org/10.1175/2010JPO4377.1.

Hasegawa, D., J. Sheng, D. A. Greenberg, and K. R. Thompson, 2011: Far-field effects of tidal energy extraction in the Minas Passage on tidal circulation in the Bay of Fundy and Gulf of Maine using a nested-grid coastal circulation model. Ocean Dyn., 61, 1845-1868, https://doi.org/10.1007/s10236-011-0481-9.

He, R., D. J. McGillicuddy Jr., B. A. Keafer, and D. M. Anderson, 2008: Historic 2005 toxic bloom of Alexandrium fundyense in the western Gulf of Maine: 2. Coupled biophysical numerical modeling. J. Geophys. Res., 113, C07040, https://doi.org/ 10.1029/2007JC004602.

Johnson, C. L., and Coauthors, 2011: Biodiversity and ecosystem function in the Gulf of Maine: Pattern and role of zooplankton and pelagic nekton. PLOS ONE, 6, e16491, https://doi.org/ 10.1371/journal.pone.0016491.

Large, W. G., and S. Pond, 1981: Open ocean momentum flux measurements in moderate to strong winds. J. Phys. Oceanogr., 11, 324-336, https://doi.org/10.1175/1520-0485(1981)011<0324: OOMFMI $>2.0 . \mathrm{CO} ; 2$.

Li, Y., R. He, and D. J. McGillicuddy Jr., 2014: Seasonal and interannual variability in Gulf of Maine hydrodynamics: 2002 2011. Deep-Sea Res. II, 103, 210-222, https://doi.org/10.1016/ j.dsr2.2013.03.001.

Longuet-Higgins, M. S., and R. W. Stewart, 1961: The changes in amplitude of short gravity waves on steady non-uniform currents. J. Fluid Mech., 10, 529-549, https://doi.org/10.1017/ S0022112061000342.

Masson, D., 1996: A case study of wave-current interaction in a strong tidal current. J. Phys. Oceanogr., 26, 359-372, https:// doi.org/10.1175/1520-0485(1996)026<0359:ACSOWI>2.0.CO;2.

Mellor, G., 2004: Users guide for a three dimensional, primitive equation, numerical ocean model. Princeton University Rep., 56 pp., http://jes.apl.washington.edu/modsims_two/usersguide0604.pdf.

Moon, I.-J., 2005: Impact of a coupled ocean wave-tide-circulation system on coastal modeling. Ocean Modell., 8, 203-236, https://doi.org/10.1016/j.ocemod.2004.02.001.

NDBC, 2009: Handbook of automated data quality control checks and procedures. NDBC Tech. Doc. 09-02, 78 pp., https://www.ndbc.noaa.gov/ NDBCHandbookofAutomatedDataQualityControl2009.pdf.

Ohashi, K., J. Sheng, K. R. Thompson, C. G. Hannah, and H. Ritchie, 2009a: Effect of stratification on tidal circulation over the Scotian shelf and Gulf of St. Lawrence: A numerical study using a three-dimensional shelf circulation model. Ocean Dyn., 59, 809-825, https://doi.org/10.1007/s10236-009-0212-7.

, and 2009b: Numerical study of threedimensional shelf circulation on the Scotian shelf using a shelf circulation model. Cont. Shelf Res., 29, 2138-2156, https://doi.org/ 10.1016/j.csr.2009.08.005.

Saha, S., and Coauthors, 2010: The NCEP Climate Forecast System Reanalysis. Bull. Amer. Meteor. Soc., 91, 1015-1057, https:// doi.org/10.1175/2010BAMS3001.1.

Sheng, J., R. J. Greatbatch, and D. G. Wright, 2001: Improving the utility of ocean circulation models through adjustment of the momentum balance. J. Geophys. Res., 106, 16711-16728, https://doi.org/10.1029/2000JC000680.

Smith, P. C., N. R. Pettigrew, P. Yeats, D. W. Townsend, and G. Han, 2012: Regime shift in the Gulf of Maine. Advancing an Ecosystem Approach in the Gulf of Maine, American Fisheries Society Symp. 79, Bethesda, MD, American Fisheries Society, 185-203.

Sun, Y., C. Chen, R. C. Beardsley, Q. Xu, J. Qi, and H. Lin, 2013: Impact of current-wave interaction on storm surge simulation: A case study for Hurricane Bob. J. Geophys. Res. Oceans, 118, 2685-2701, https://doi.org/10.1002/jgrc.20207.

Thompson, K. R., and J. Sheng, 1997: Subtidal circulation on the Scotian shelf: Assessing the hindcast skill of a linear, barotropic model. J. Geophys. Res., 102, 24 987-25003, https:// doi.org/10.1029/97JC00368.

-, K. Ohashi, J. Sheng, J. Bobanovic, and J. Ou, 2007: Suppressing bias and drift of coastal circulation models through the assimilation of seasonal climatologies of temperature and salinity. Cont. Shelf Res., 27, 1303-1316, https://doi.org/10.1016/ j.csr.2006.10.011.

Tolman, H. L., 1990: The influence of unsteady depths and currents of tides on wind-wave propagation in shelf seas. J. Phys. Oceanogr., 20, 1166-1174, https://doi.org/10.1175/15200485(1990)020<1166:TIOUDA > 2.0.CO;2.

_ , and Coauthors, 2014: User manual and system documentation of WAVEWATCH III version 4.18. NOAA Marine Modeling and Analysis Branch Tech. Note 316, 311 pp, http:// polar.ncep.noaa.gov/waves/wavewatch/manual.v4.18.pdf.

Urrego-Blanco, J., and J. Sheng, 2012: Interannual variability of the circulation over the eastern Canadian shelf. Atmos.-Ocean, 50, 277-300, https://doi.org/10.1080/07055900.2012.680430.

Vincent, C. E., 1979: The interaction of wind-generated sea waves with tidal currents. J. Phys. Oceanogr., 9, 748-755, https://doi.org/ 10.1175/1520-0485(1979)009<0748:TIOWGS $>2.0 . C O ; 2$.

Wang, P., and J. Sheng, 2016: A comparative study of wave-current interactions over the eastern Canadian shelf under severe weather conditions using a coupled wave-circulation model. J. Geophys. Res. Oceans, 121, 5252-5281, https://doi.org/ 10.1002/2016JC011758.

Xie, D., and Q. Zou, 2016: Effect of wave-current interaction on waves and circulation over Georges Bank during storm events. Proc. 35th Conf. Coastal Engineering, Antalya, Turkey, International Conference on Coastal Engineering, 18, https:// doi.org/10.9753/icce.v35.waves.18.

Xue, H., F. Chai, and N. R. Pettigrew, 2000: A model study of the seasonal circulation in the Gulf of Maine.J. Phys. Oceanogr., 30, 1111-1135, https://doi.org/10.1175/1520-0485(2000)030<1111: AMSOTS $>2.0 . \mathrm{CO} ; 2$. 